\title{
AN INVESTIGATION OF PALEO-WILDFIRES DURING THE CRETACEOUS- PALEOGENE (K-PG) BOUNDARY AT EL KEF, TUNISIA
}

\author{
Michael A. Gross \\ Department of Geology \\ University of Colorado, Boulder
}

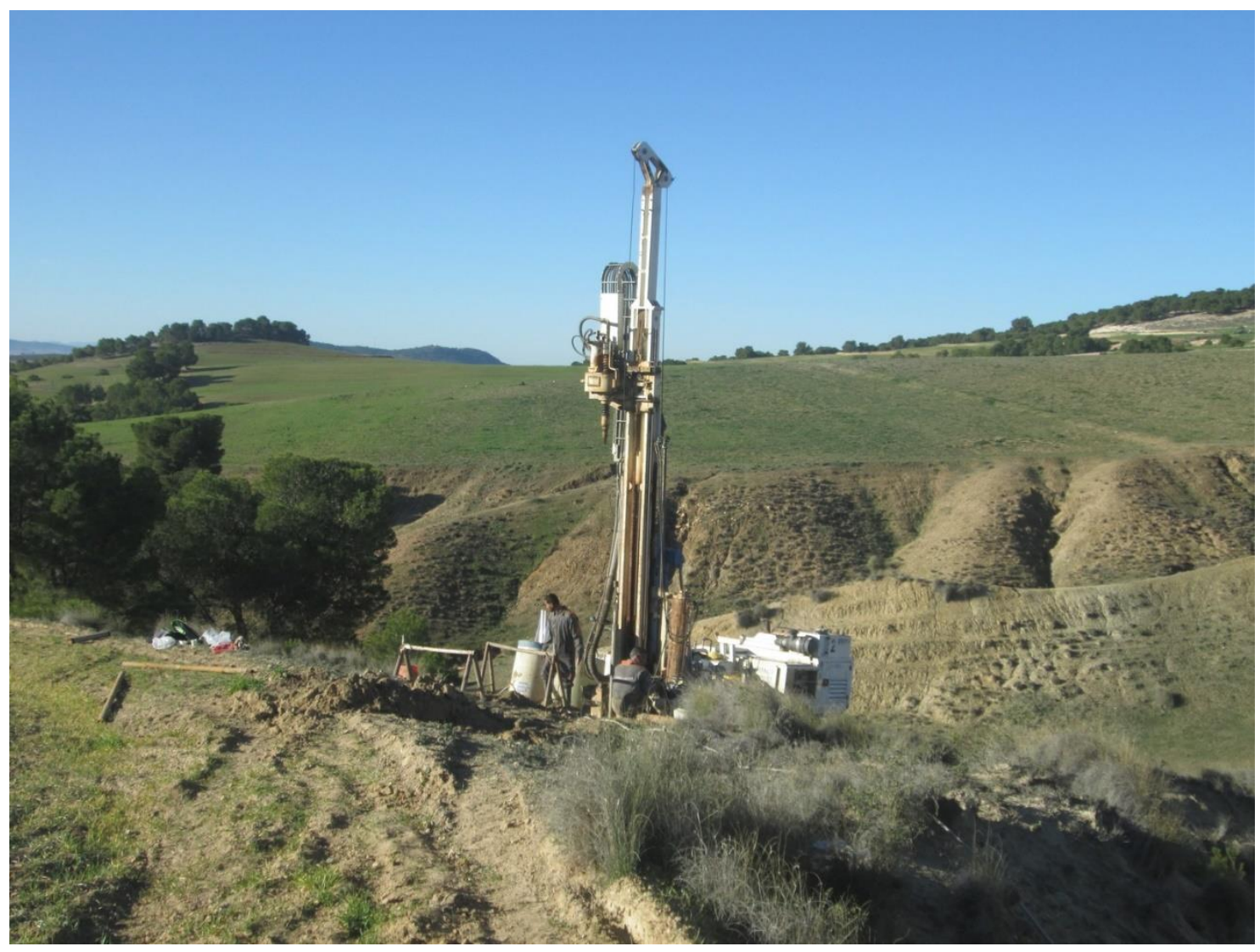

Thesis Advisor

Dr. Julio Sepúlveda, Department of Geological Sciences

Committee Members

Dr. Charles Stern, Department of Geological Sciences

Dr. Eve-Lyn Hinckley, Department of Environmental Studies

The University of Colorado, Boulder

April $10^{\text {th }}, 2017$ 


\section{TABLE OF CONTENTS}

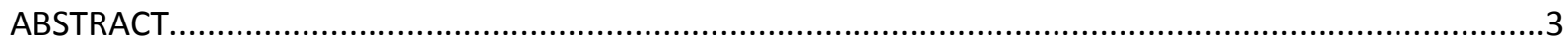

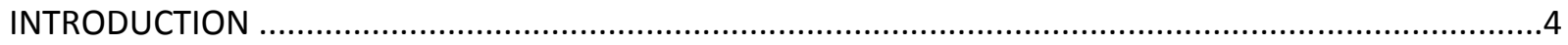

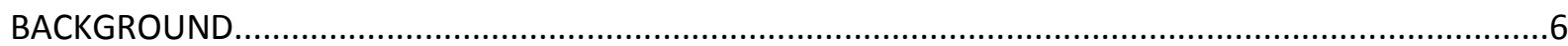

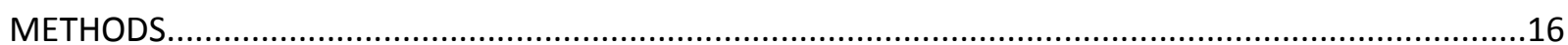

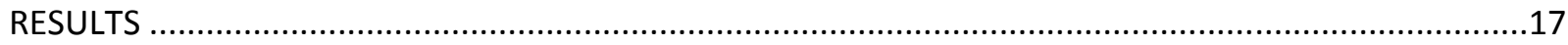

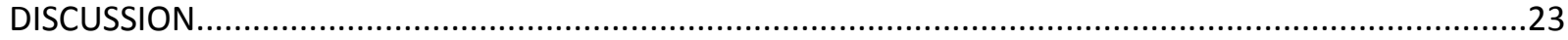

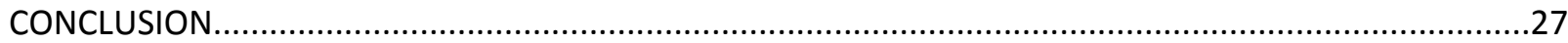

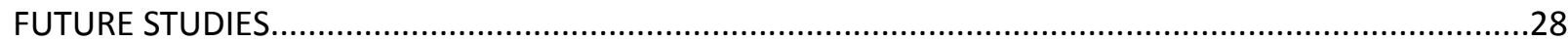

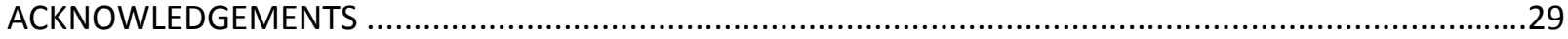

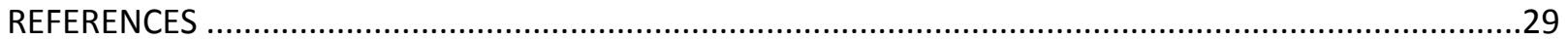

Title Page Photo. The view of a sampling locality at El Kef Tunisia. Taken from the El Kef Coring Program website http://www.ktboundary.org/ 


\section{Abstract}

The causes and consequences of the Cretaceous-Paleogene mass extinction have long been a source of contention. Several models predict that enough thermal radiation from the bolide impact was produced to ignite wildfires at least regionally and possibly on a global scale, raising average temperatures by up to $\sim 10^{\circ} \mathrm{C}$, and releasing large amounts of $\mathrm{CO}_{2}$ and $\mathrm{CO}$. However, the role of regional versus global wildfire events as an environmental stressor, as well as the sources of the fire (land vegetation vs. hydrocarbon reservoirs) and its expression in terrestrial and marine archives, remains controversial. Typically, wildfires are preserved in the geologic record by features such as charcoal and soot deposition. Additionally, molecular fossils (biomarkers) like polycyclic aromatic hydrocarbons (PAHs) and long-chain $n$-alkanes preserved in marine sedimentary sequences can be diagnostic of biomass burning (including sources and temperature of combustion) and terrestrial input to the marine realm, respectively. Using Gas Chromatography- Mass Spectrometry, we investigated the abundance of these biomarkers in the K/Pg global stratotype and section point (GSSP) of El Kef, Tunisia. Our results indicate the occurrence of a spike in PAH concentration and vegetation proxies for a few thousand years immediately above the $\mathrm{K} / \mathrm{Pg}$ boundary. These results are like those found in the marine section of Caravaca, Spain and demonstrate that wildfires and enhanced terrestrial input following the $\mathrm{K} / \mathrm{Pg}$ may have been more widespread features of this event than previously recognized. Finally, a dominance of 4-5 ringed PAHs is consistent with moderate-high intensity.

Keywords: K-Pg, Mass Extinction, Biomarkers, PAHs, Wildfires, Paleoclimate 


\section{Introduction}

Roughly 66 million years ago, at the Cretaceous-Paleogene (K/Pg) boundary, an extraterrestrial object struck the earth and is hypothesized to have caused one of the largest mass extinction events the planet had seen during the Phanerozoic (LaMolda 2005). Consequently, the course of life's evolution altered drastically including the rise of mammals (Archibald 2002). The first signs of an impact at the K-Pg event were detected with the enrichment of iridium, a metal rare in the Earth's crust but more common in asteroids, in rocks across the K/Pg by Luis Alvarez in 1980 (Alvarez et al. 1980). Subsequently, the impact crater itself was discovered in the Chicxulub crater, Mexico (Hildebrand et al. 1991). There is, however, much dispute as to the exact workings of the extinction event itself, and in response, a large body of research has been produced since then. Although the extinction mechanisms are still unclear, there are well-established first principles from which to begin exploring.

A common hypothesis is the global firestorm theory wherein a bolide several kilometers long impacted the earth, heating the atmosphere and igniting wildfires worldwide. The soot produced from those wildfires would then cause an albedo effect causing global cooling bringing surface temperatures to near freezing and slowing the hydrological cycle preventing precipitation and causing global drought. Sulfur aerosols from the target rock would vaporize and react with water in the atmosphere and precipitate out as acid rain negatively impacting calcareous plankton.

In the same fashion macro and nannofossils are deposited in the geologic record, so too are molecular fossils. Using the 'Biomarker Concept', one can imply and infer certain paleoenvironment conditions, from ancient sea surface temperatures to the arrival of humans in certain valleys. There are considerations to be made, however, regarding the depositional environment and how that will relate to the diagenesis of organic molecules. In biomarkers, there is a certain tradeoff between levels of information classes of organics can provide and 
their preservation potential (Fig. 1). The best biomarkers can then describe accurately biological source of their formation whilst others can only offer moderate information. A multi-proxy

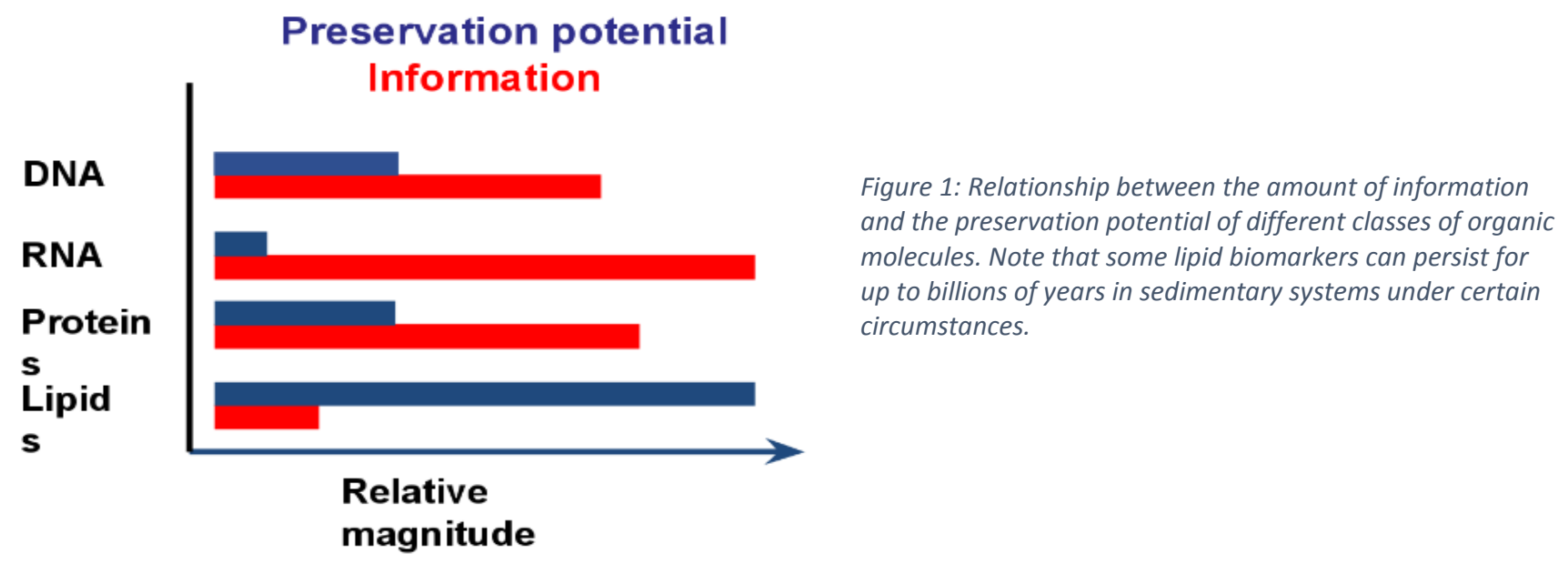

toolset is then used to effectively reconstruct the conditions of the organics deposition. This then presumes that the rocks that biomarkers are stored in are sedimentary. Organics do not persist however under conditions where oxygen is pervasive. A molecules presence in the record indicates then that the precursor was there for enough time for it to be buried in the geologic record. For example, if certain group of organisms with a specific biomarker were to go extinct, you would see a sudden drop in the concentration of their biomarker and vice versa if they were to experience sudden population increase.

This study provides a detailed report of organic molecules (biomarkers) across the K/Pg at the stratotype section from El Kef, Tunisia. This data is the first high-resolution organic geochemical record from a continuous drilling core (El Kef Drilling Program) from this area, wherein 160 m of core were recovered. This study focuses on two major classes of biomarkers: (a) polycyclic aromatic hydrocarbons, which are proxies for wildfires, and (b) both short- and long-chain $n$-alkanes, which are proxies for aquatic and terrestrial input, respectively. This data will then be employed to test the likelihood of the global firestorm hypothesis in the K-Pg mass extinction. 

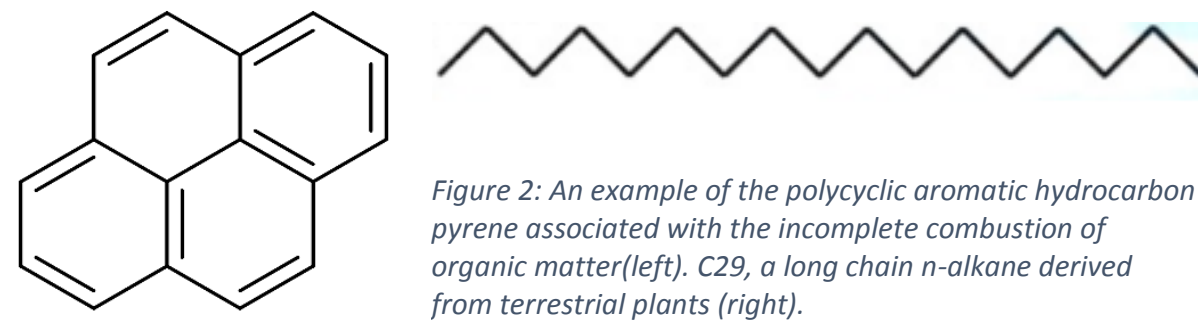

\section{Background}

\subsection{First Principles of the $\mathrm{K} / \mathrm{Pg}$ extinction}

What is initially evident throughout numerous sections across the K-Pg is a worldwide decline in the percentage of calcium carbonate $\left(\% \mathrm{CaCO}_{3}\right)$, which is thought to relate to the productivity of calcareous primary producers such as nannoplankton, and heterotrophic organisms such as planktonic foraminifera (Fig. 3). Units include two of the most expanded and well resolved sections, Caravaca, Spain and El Kef, Tunisia, and other sections such as Bidart, France and Agost, Spain (Alegret 2003). At El Kef, calcite across the K/Pg, drops from $40 \%$ in the late Cretaceous to $0 \%$ in the early Danian (Keller and Lindinger 1989)

Whilst $\% \mathrm{CaCO}_{3}$ indicates the productivity of calcareous organisms, processes like water column $\mathrm{pH}$ /dissolution and terrestrial input can obscure the signal from biogenic $\mathrm{CaCO}_{3}$, and so the depositional environment must be well understood (Punekar 2015). Extensive calcareous planktonic nannofossil assemblages at and around boundary in the Tethys Ocean areas of EI Kef, Tunisia and Caravaca, Spain also support a sudden change in productivity for calcareous phytoplankton. In Caravaca, the upper Maastrichtian below the boundary displays an accelerated decline with an absolute abundance loss of $82.5 \%$ in the transitional layer for calcareous nannofloras. Taxa that originally comprised a minor component of assemblages increase by an order of magnitude after the boundary (LaMolda 2005). At El Kef, traces of 
extinction are observed by algal and faunal turnover at the boundary. Sudden appearance of 'survivor taxa' and their eventual dominance above the boundary record this event (Keller 1995). Though Cretaceous taxa are sometimes present above the boundary, it has been proposed that they reappear due to reworking (Jiang and Gartner 1986).

The carbon isotopic analysis of bulk carbonate and calcareous plankton has been used to determine the amount of reworking around the boundary. An abrupt negative carbon isotopic excursion (CIE) in the $\delta^{13} \mathrm{C}$ values of bulk carbonate and calcareous plankton is observed after the $\mathrm{K} / \mathrm{Pg}$ boundary, where $\delta^{13} \mathrm{C}$ becomes increasingly negative (depleted in ${ }^{13} \mathrm{C}$ vs ${ }^{12}$ C) (Smit 1982, Keller \& Lindinger 1989) (Fig. 2). As the CIE is ubiquitous, if calcareous plankton above the boundary reflect the same $\delta^{13} \mathrm{C}$ as before the boundary, then it is proposed that they were reworked into the sediments above. This was the reasoning of Kaiho et al. at Caravaca where 12 planktonic foraminiferal species all exhibited the same $\delta^{13} \mathrm{C}$, and not reflecting the excursion (Kaiho Lamolda 1999). All the above conclusions establish that $\% \mathrm{CaCO}_{3}$, calcareous assemblages and their test chemistry indicate a selective reduction in primary production for calcareous phytoplankton and foraminifera.

The macrofossil record, on the other, hand shows an almost instantaneous extinction of non-avian dinosaurs, marine and flying reptiles, and ammonites (Fastovsky D.E., Sheehan P.M

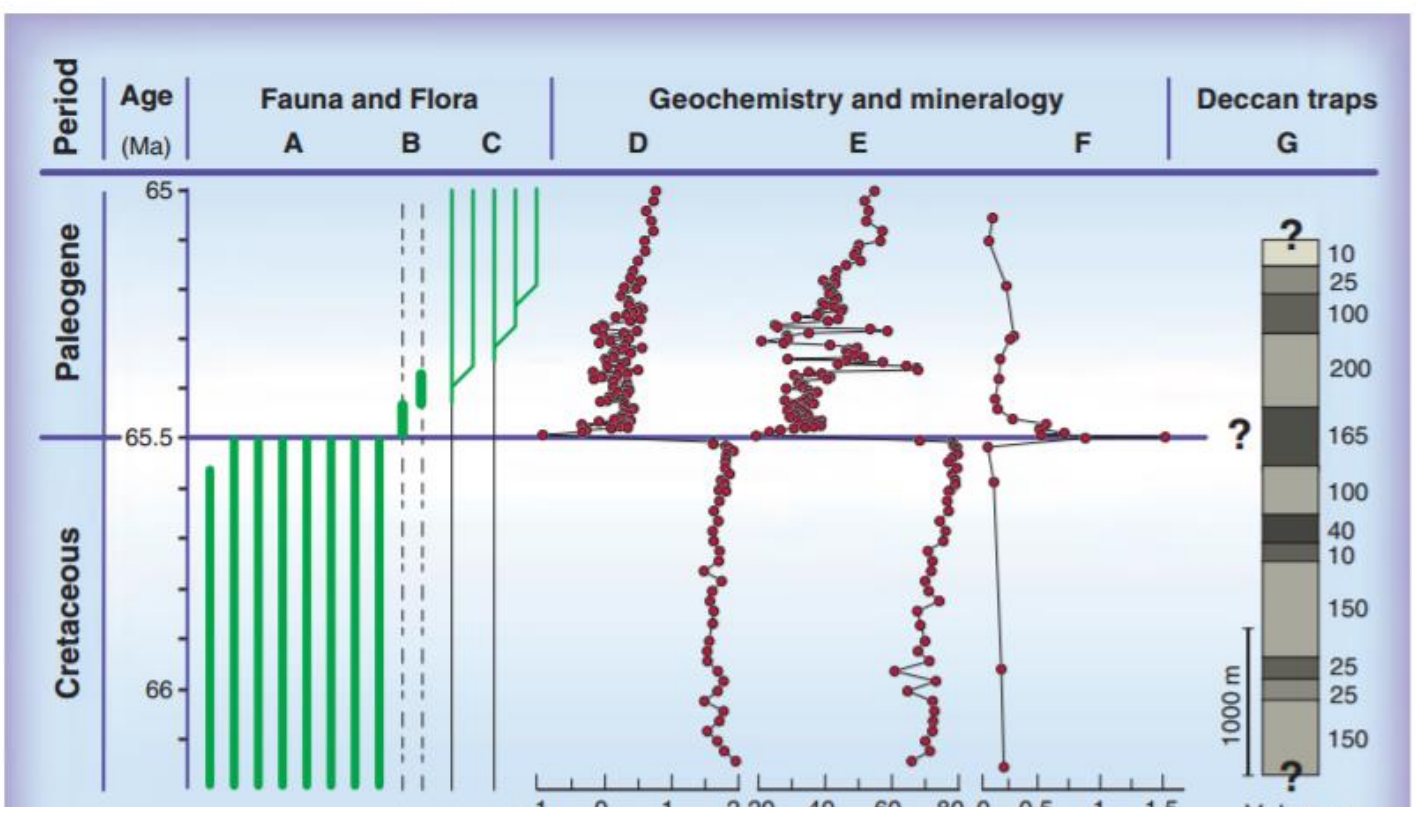

Figure 3: A stratigraphic record of biological events across the $\mathrm{K}-\mathrm{Pg}$ boundary in conjunction with chemical records from the North American Ocean Drilling Program, as well as the Deccan flood basalt units in India. Figure from Schulte et al 2010. 
2005). The working of these extinctions is still controversial but many of these organisms were dependent on primary productivity directly. Only $12 \%$ of the land-dwelling forms survived, while $90 \%$ of species in the freshwater assemblage survived, because large land-dwelling forms were dependent directly on primary productivity, while the fresh water assemblages (crocodilians) and small burrowing mammals could have relied on detritus for considerable periods of time (Sheehan, P. M. \& Fastovsky, D. E. 1992). In fact, the first 5 My of the Paleogene displays rapid radiation of mammalian species typical of post traumatic rebound (Maas and Krause 1994, Alroy 1999,Archibald and Deutschman 2001), and it's been reported that 17 of 18 mammalian orders did not exist before the boundary (Archibald 2002).

Lastly, an abundance of soot was discovered and presented by Wolbach et al. (1985, 1988, 1990), and Hildebrand and Wolbach (1989) around the K-Pg boundary in New Zealand, North American, and Europe. This spike in elemental carbon is reported as being up to $0.012 \mathrm{~g}$ $\mathrm{cm}^{-2}$, which must have required a large amount of land biomass to combust, and/or the target rock to contain a hydrocarbon reservoir (Belcher et al. 2006).

\subsection{Possible Causes of Extinction}

Several hypotheses have been set forth to explain the K-Pg fallout yet the mechanisms and timing of extinction are still under dispute. A thermal pulse from the falling bolide itself could have extinguished large swathes of species from atmospheric heating alone. Yet, the

impactor blast radius is not large enough to cause a worldwide event per se (Melosh et al. 1990). However, the vaporization of impact ejecta and source rock could have re-entered the stratosphere to eventually slowly rain down over the entire Earth as a firestorm, further raising surface temperature to the point of wood ignition for at least several hours. This would then explain the near level distribution of the Iridium anomaly (Melosh et al. 1990) and soot layer worldwide. The thermal irradiance required to ignite wood $\left(29.3 \mathrm{~kW} \mathrm{~m}^{-2}\right)$ is above the predicted thermal irradiance of $10 \mathrm{~kW} \mathrm{~m}^{-2}$ after accounting for radiation into space as well as absorption by greenhouse gases. However, since the re-entry could last for several hours, an irradiance of $12.5 \mathrm{~kW} \mathrm{~m}^{-2}$ with local variability could easily derive in fires. Even if the impact did not cause 
ignition in the first few hours, the delivered thermal pulse could have caused plant desiccation and wholesale death that would provide the perfect fuel to later be ignited (Melosh et al. 1990).

Originally, Alvarez et al. 1980 invoked global darkening from dust and other particulates being responsible for blanketing the earth and inhibiting photosynthesis (Alvarez et al. 1980), which may have been the primary cause of extinction. However, Pope et al. (2002) proposes that the importance of dust is negligible. In fact, grain size distribution of the clastic debris from the boundary indicate that the amount of sub-micrometer size dust is two orders of magnitude less than what is necessary to block out the sunlight transmission. Small grain size is required to remain suspended long-enough in the atmosphere to seriously inhibit photosynthesis, as coarser grains will fall out due to their higher density (Pope 2002).

Other particulates like sulfate aerosols and soot from post impact fires may have inhibited sunlight from reaching the surface (Pope et al. 1997,Wolbach et al. 1990). This is consistent with the fossil record that shows a marked decrease in calcareous phytoplankton, which would be most affected by the availability of their energy source, light. There is however, no observed drop in productivity for other non-calcareous phytoplankton. Sulfate aerosols would have a slightly longer residence time ( 12 years) in the stratosphere compared to particles until they would precipitate out as acid rain (Pope et al. 1997). During this time, those aerosols particulates could decrease global temperatures significantly. However, studies by Sohsuke Ohno indicate that if source rocks contain anhydrite $\left(\mathrm{CaSO}_{4}\right)$, sulfur trioxide would be the dominant form of sulfur formed from source rocks (Ohno, S. et al. 2014). This sulfur trioxide would then react with water to form sulfuric acid aerosol particles that would then be quickly scavenged, even in a matter of days, by larger silicate particles (dust) bringing acid rain to the surface, and causing an abrupt ocean acidification which would selectively harm calcareous plankton (Ohno, S. et al. 2014).

Black carbon (BC, or soot) would have been flushed relatively quickly from rain if present in the troposphere. Though if present in the stratosphere, where it could reside for years causing significant climatic change, soot then becomes the principle culprit for cooling 
episodes. The impact event would be responsible for an injection of $\mathrm{BC}$ from the incomplete combustion of a carbon source into the stratosphere, efficiently absorbing solar radiation and reducing the amount of sunlight reaching the Earth's surface, which leads to heating of the stratosphere and cooling of the troposphere. As less sunlight reaches the surface, global sea surface temperatures would decrease, reducing precipitation, and possibly creating drought-like conditions on land from $15^{\circ} \mathrm{N}$ to $15^{\circ} \mathrm{S}$.

Kunio Kaiho uses a model with varying carbon injections to suggest that the cooling event was not as severe as previously thought, and predicts that at the lower end of $500-\mathrm{Tg} \mathrm{BC}$, surface temperatures would decrease by $6-9{ }^{\circ} \mathrm{C}$. This cold spell would last for roughly two years on land causing a $45-70 \%$ reduction in precipitation from a weakened hydrological cycle. The middle of 1500-Tg BC and upper bound of 2600-Tg BC would induce lowering of surface temperatures by $10-16{ }^{\circ} \mathrm{C}$ and $10-18{ }^{\circ} \mathrm{C}$, respectively, with precipitation reducing by $55-80 \%$ and $60-85 \%$ for a period of three and five years, respectively. These authors further propose that a latitudinal effect took place, where global cooling was more pronounced at higher latitudes (Kaiho et al. 2016).

Temperature-stressed ecosystems would not be able to rebound so quickly, and herbivorous dinosaurs would overgraze, eliminating most primary production on land (Kaiho et al. 2016). Organisms able to shield themselves via burrowing or by been underwater would be able to survive from the original impact and ejecta. Further survival would require an ability to rely on detritus for appreciable amounts of time as primary production would have been heavily reduced in the first couple of years after impact. Such organisms include crocodilians, birds, mammals, fish and small reptiles (Sheehan, P. M. \& Fastovsky, D. E. 1992), all of which have the traits essential to live through an 'impact winter'. Dinosaurs would not be able to cope without migrating to higher latitudes for food and be subject to 
greater stress, whilst crocodilians, who do not migrate and inhabit the same waters all year long would be selected to persist (Kaiho et al. 2016).

a

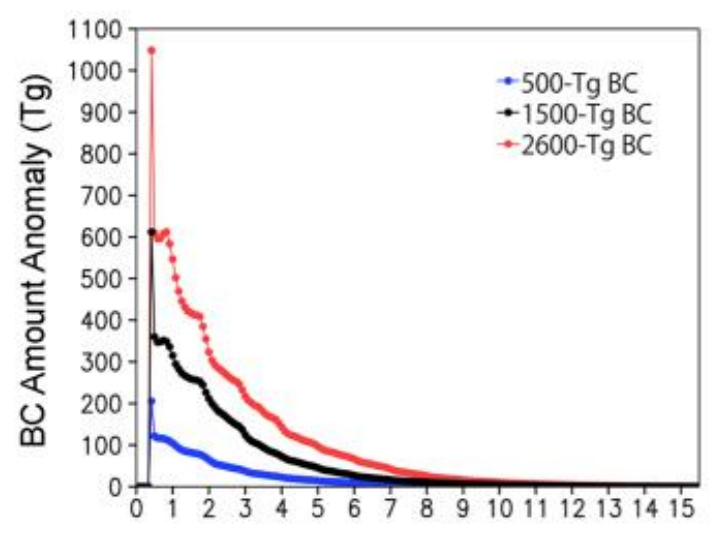

C

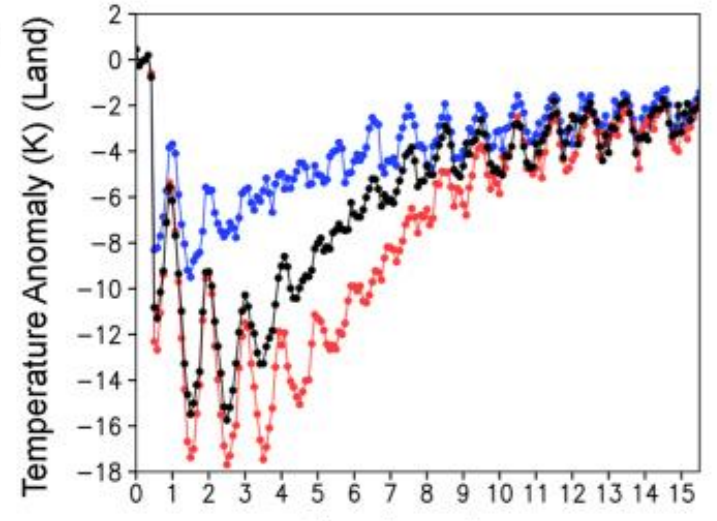

b

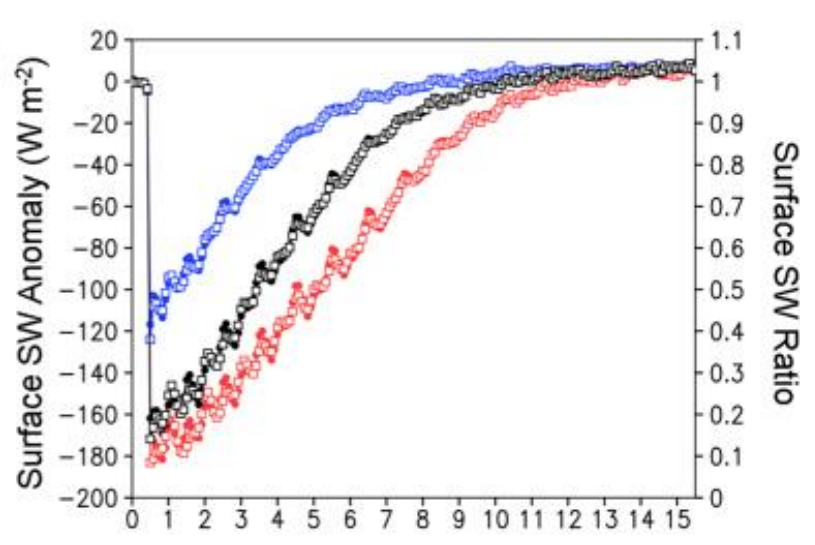

d

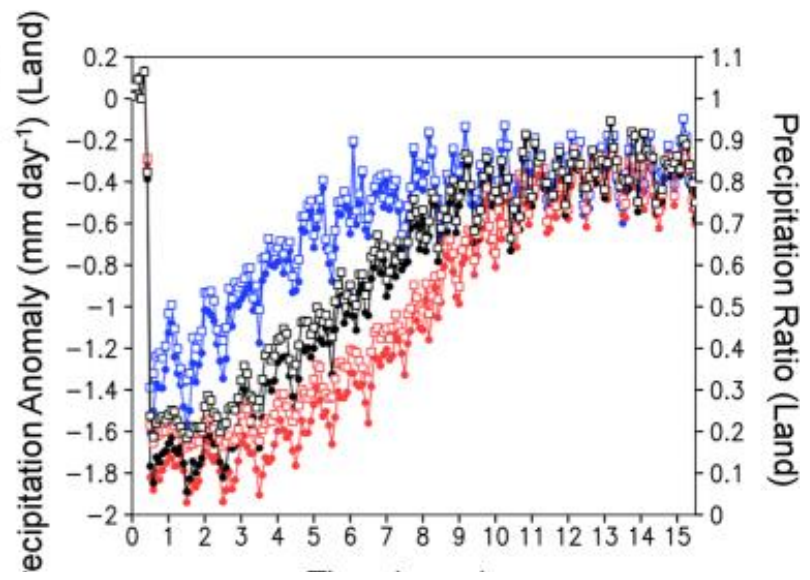

Figure 4: Models predicting temperature and precipitation changes correlated with BC injections into the stratosphere. (SW=shortwave radiation). Figure from Kaiho et al.2016.

\subsection{Origin of Soot: Global wildfires or hydrocarbon burning?}

Whilst it is obvious that a carbon source is necessary to produce all that soot found across the $\mathrm{K} / \mathrm{Pg}$, whether it came from the target rock itself or from biomass burning remains contentious. Different lines of evidence support either hypothesis.

Typically, records of wildfire are preserved in sediments in the form of charcoal, where the volatile elements of plants are driven off leaving an elemental carbon residue. Yet, charcoal evidence in North America remains scant, which suggests the idea of a non-biomass combustion (Belcher et al. 2009). Goldin and Melosh (2009) revisited the model in Melosh 
(1990) and stated that the amount of ejecta would shield the underlying forests from their own radiation, bringing the thermal pulse to below the point of ignition for wood (Goldin \& Melosh 2009). Instead, Belcher (2009) proposes that the source of soot was a hydrocarbon reservoir (either coal or oil), and this would explain the drop in charcoal at the boundary when compared to surrounding sediments. Furthermore, $\mathrm{BC}$ across the $\mathrm{K} / \mathrm{Pg}$ has a uniform $\delta^{13} \mathrm{C}$ signature pointing to a single source, and a morphology typical of oil combustion (Belcher et al. 2006). Another issue with the global wildfire hypothesis is the presence of non-charred plant remains that somehow avoided conflagration (Belcher et al. 2006). The source of BC would also have to have enough energy to infiltrate the stratosphere to cause the global cooling episode, while wildfires typically do not inject particles into the stratosphere (Sofiev et al. 2013).

A more direct and reliable marker for wildfires is the presence of a class of organic molecules that are formed from the incomplete combustion of organic matter, called Polycyclic Aromatic Hydrocarbons (PAHs). PAHs are excellent diagnostic markers for paleoclimate reconstruction as they not only indicate the source of burned material but also the temperature of the fire at which these molecules were formed, as reflected in their degree of cyclization. Wolbach et al. (1988) suggested that some of the strongest lines of evidence for the wildfire hypothesis can be found in PAHs. PAHs can also be products of terrestrial input and diagenesis, as several plants and fungi produce molecules that are precursor for PAH molecules.

Elevated levels of the pyrogenic PAHs phenanthrene, anthracene, pyrene and flouranthene were reported across the K-Pg boundary in sections at New Zealand, Italy, and Denmark, substantiating the wildfires hypothesis during the event, the first evidence of its kind (Venkatesan and Dahl, 1989). Arinobou et al. (1999) analyzed a sample of the K-Pg boundary from the marine section of Caravaca, Spain and found an enrichment as high at 112 to 154 fold for the pyrosynthetic compounds coronene, benzo(g,h,i)perylene, and benzo(e)pyrene, all of which are 5- and 6-ringed structures, and which are proxies for high temperatures of combustion. Belcher (2009) also reported a spike in PAHs in the K-Pg well above the background in multiple continental sections across north America (Belcher et al. 2006). All the PAHs in Belcher (2009) were low in the degree of cyclization (2-3 rings), which is indicative of low temperatures of combustion. Belcher (2009) goes on to state that a comparison of PAH 
abundances in samples and combustion products of coal and other hydrocarbons are very similar, and concludes that PAHs were most likely sourced from an impact rock (Gilmour 2003).

In contrast, Robertson (2012) responds to Belcher (2005) claims regarding the soot morphology in that her samples were unrepresentative samples of a smoke plume, as they were collected from a burnt-out forest floor (Robertson 2012). Robertson (2012) explains that the soot morphology can also be indicative of wood or hydrocarbon combustion (Novakov et al. 1997). The charcoal anomaly could then be explained by the combustion of charcoal by high intensity flames, and their values are not corrected for rates in sedimentation, which can vary through an impactor event. The North American samples analyzed by Belcher (2009) were close to the impact, so the scenario of no fires would seem unlikely, while charcoal from distal sites would be more useful.

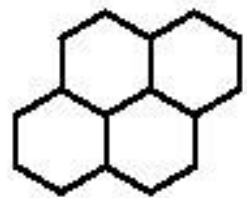

Pyrene<smiles>C1CCC2C(C1)CCC1CCCCC12</smiles>

Phenanthrene<smiles>C1CCC2CCCCC2C1</smiles>

Naphthalene<smiles>C1CCC2C(C1)CCC1CCC3CCCCC3C12</smiles>

Benzo[c]phenanthrene<smiles>C1CCC2CC3CC4CCCCC4CC3CCC2C1</smiles>

Benz[a]anthracene<smiles>C1CCC2CC3CCCCC3CC2CC1</smiles>

Anthracene<smiles>C1CCC2C(C1)C1CCCCC1C1CCCCC21</smiles>

Triphenylene<smiles>C1CCC2C(C1)CCC1C3CCCCC3CCC21</smiles>

Chrysene

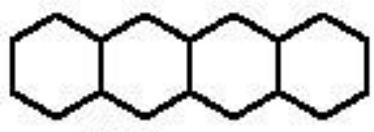

Tetracene

Figure 5: Chemical structures of PAHs used for paleo-wildfire reconstructions.

Furthermore, Robertson (2012) discusses some of the issues of the thermal pulse model proposed by Goldin and Melosh (2009). One pitfall is the non-inclusion of the scattering from falling particles. Since particulates raining down are solid and not gaseous, a transfer of heat energy is non-elastic and in some glassy spherules actually reflect radiation back to the surface. 
Thus, the model by Goldin and Melosh (2009) may overestimate the amount of shielding that the ejecta could provide. Even so, the lower thermal pulse they calculated could have still caused ignition of tinder, which most often starts fires (Robertson 2012). Another issue is the amount of soot produced and how much carbon would have to be in impact rocks to cause the global spread of soot. Robertson (2012) concludes that in situ carbon from the crater is inadequate to coat the earth in the soot layer, especially because the large portion of hydrocarbons would be converted to $\mathrm{CO}_{2}$. Also, the impactor diameter that Harvey et al. (2008) used for their calculations is too large, and the impact would only ignite carbon in a smaller diameter(Robertson 2012). As stated by Kaiho et al. (2016), wildfire smoke generally does not enter the stratosphere, but there are studies that indicate otherwise, and the mechanics of pyro-cumulonimbus injections of smoke from massive wildfires are poorly understood (Fromm 2008). Non-charred remains also could be due to depositional environment, e.g., being underwater at the time of conflagration, whereas thermal models are still being revisited. Lastly, the PAHs concluded by Belcher 2009 to be combusted from hydrocarbons can also be formed from wildfires. An impact that landed below sea level would hardly cause a low temperature oil fire, as is reported by Belcher 2009.

\subsection{Geologic Setting of the El Kef section in northern Tunisia}

Named for the town of El Kef in Northwestern Tunisia, the outcrop section lies about seven $\mathrm{km}$ west of the town (Fig. 5). El kef is an extremely well resolved section as well as being one of the more complete sections of the K-Pg boundary. This is due to high rates of sedimentation and a shallow depositional environment. Because of all these properties, the El Kef section was designated the Global Boundary Stratotype Section and Point (GSSP) for the K-Pg boundary in the International Commission on Stratigraphy. All other sections thought to be K-Pg would be compared to this section. The section was deposited in a shallow part of the sea near the coast and on the continental shelf at a paleodepth of about $200 \mathrm{~m}$, and a paleolatitude of $20^{\circ} \mathrm{N}$ (Giron 2013). At the outcrop, the section is defined by a chalk marl layer that has a lithologic break to a $55 \mathrm{~cm}$ thick clay rich in organics and poor in calcium carbonate (Fig. 6). At the base of the boundary clay is a 2-3 mm oxidized iron layer of red hue. This red layer is present in all 
complete K-Pg boundaries (Keller 1995). The Ir anomaly characteristic of the K-Pg is generally in that red layer as well as Ni-rich Spinels (Robin et al. 1991).
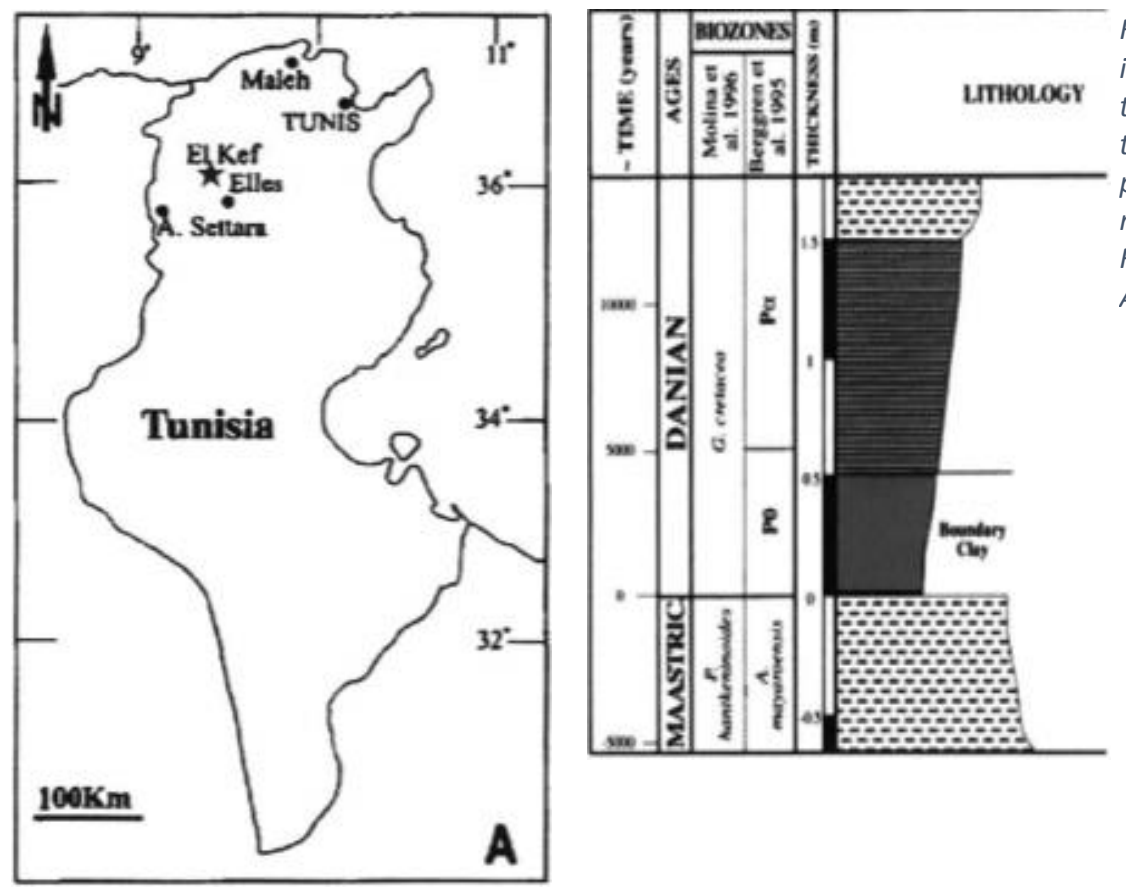

Figure 6: Location of El Kef (black star) in Tunisia and stratigraphic column of the $\mathrm{K} / \mathrm{Pg}$ section. The $\mathrm{K}-\mathrm{Pg}$ correspond to the $0 \mathrm{~cm}$ horizon. The hatched

pattern is marl, horizontal stripes being marly clay, and solid gray denotes clay. Figures from Giron (2013) and from Arenillas et al., (2002) (Giron 2013)

The outcrop section is partially weathered, exposed to possible contaminants. IN order to obtain fresh, unweathered material across the $\mathrm{K} / \mathrm{Pg}$ from El Kef, four holes were drilled in December 2013 and January 2014 as a part of the El Kef Drilling Program (Fig. 6), led by Professor Hedi Negra and Graduate Assistant Marwa Baroumi of the University of Tunis. A total of 160 meters of cores were retrieved and processed at the IODP Core Repository at the University of Bremen, Germany. Dr. Julio Sepulveda, a member of the El Kef Drilling Program Science Team acquired samples throughout the cores, from which a pilot subset of 45 highresolution samples were processed and analyzed for this thesis. This study focuses on $\sim 5.5$ meters across the K/Pg of core A (Fig. 6). Previous reports on sedimentation rates across the $\mathrm{K} / \mathrm{Pg}$ range between $8.5 \mathrm{~cm} / \mathrm{kyr}$ on average for Maastrichtian sedimentation and 7.96 (+- 1.30) $\mathrm{cm} /$ kyr on average for the Boundary Clay sedimentation rate (Giron 2013). 


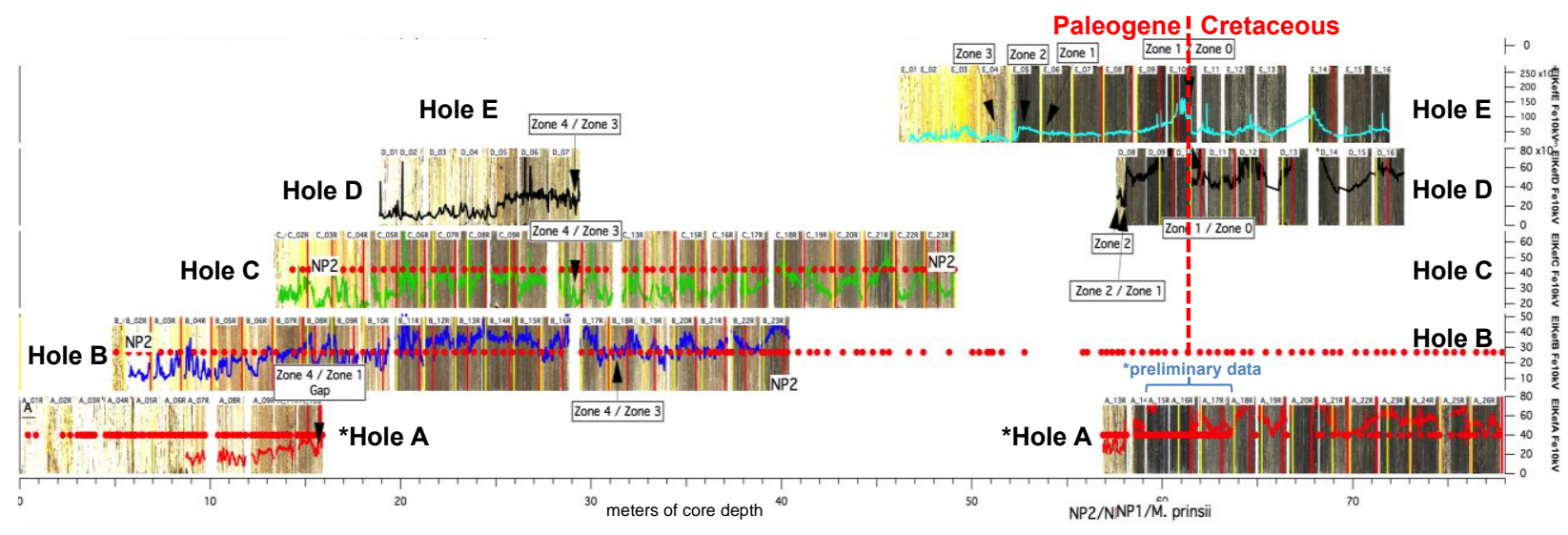

Figure 7: Composite images, XRF iron counts (Fe 10kV) and calcareous nannoplankton biostratigraphy of Holes A-E indicate the presence of a continuous sedimentary sequence covering the late Cretaceous and early Paleogene. Figure courtesy of $U$. Rohl and T. Westerhold (U. Bremen; images and XRF data) and T. Bralower (PSU; biostratigraphy). This study presents preliminary results from cores $1 A-15 R$ to $1 A 17 R$.

\section{Methods}

\subsection{Sample preparation}

Core samples were cleaned by scraping a few mm off the surface with solvent cleaned scrapers, and then ground using a ceramic mortar and pestle that was previously cleaned three times with a polar gradient of solvents. After samples were pulverized, they were then extracted using an Automated Solvent Extractor (ASE) and a mixture of dichloromethane and $\mathrm{MeOH}(9: 1)$ for a total of three times, or until the solvent extracts became colorless. Before extraction, a mix of internal standards of known concentration was added to each sample. The extracts were then evaporated and combined. Elemental sulfur was removed using copper shots activated with $\mathrm{HCl}$ that were added and allowed to sit overnight. Samples were then filtered through Pasteur pipettes filled with glass wool, sand mixed with sodium sulfate, and a small amount of silica gel. After filtration, samples were weighed to calculate Total Lipid Extract (TLE) yield and then underwent asphaltene separation. Asphaltenes were separated from maltenes by precipitation in hexane followed by sonication for twenty minutes, placed in the freezer for a minimum of two hours, and then centrifuged for 10 minutes at 3,000 r.p.m. Following the precipitation of asphaltenes, the maltene fraction was transferred to a vial and the centrifuge 
vial would be filled again with hexanes and the process was repeated to a total of three times. Maltenes were then evaporated and weighed, and then separated into three lipid classes by column chromatography using small Pasteur pipettes filled with glass wool, sand, and silica gel covered with some glass wool on top. The elution mixtures were Hexanes for the aliphatic fraction, Hexanes:DCM (8:2) for the aromatic fraction, DCM:MeOH (8:2) for the polar fraction.

\subsection{Sample Analysis}

After column chromatography, the fraction 2 of samples were evaporated and filled with a solution of 50uL of Hexanes:DCM 1:1. Normally samples are dissolved in Hexanes before Gas Chromatography-Stable Reaction Monitoring-Mass Spectrometry (GC-SRM-MS), but due to issues of solubility associated with the standards, we used the above solvent ratio. PAHs were analyzed on a Thermo Trace 1300 gas chromatograph interphase to a TSQ 8000 EVO triple quadrupole mass spectrometer. The oven temperature was held at $60^{\circ} \mathrm{C}$ for 2 min rose to $150^{\circ} \mathrm{C}$ with a ramp of $15^{\circ} \mathrm{C} / \mathrm{min}$. Finally, the temperature could rise to 315 and held there for $24 \mathrm{~min}$. PAHs were separated using a DB-5 column (60 meters of length, a diameter of $0.250 \mathrm{~mm}$ and a film of $0.25 \mu \mathrm{m})$.

$n$-alkanes and total steranes and hopanes were analyzed using a Waters AutoSpec Ultima double focusing magnetic sector mass spectrometer interfaced with a $6890 \mathrm{~N}$ gas chromatograph. The column in the GC was a DB-1 fused silica capillary column (sixty meters long, $0.25 \mathrm{~mm}$ diameter and 0.250 and $25 \mu \mathrm{m}$ film). The oven temperature was $60^{\circ} \mathrm{C}$ for $2 \mathrm{~min}$ and rose to $150^{\circ} \mathrm{C}$ with a ramp of $10^{\circ} \mathrm{C} / \mathrm{min}$. Finally, the temperature could rise to 315 and held there for $24 \mathrm{~min}$. The AutoSpec source has an electron ionization of $70 \mathrm{eV}$ at $250^{\circ} \mathrm{C}$.

\section{Results}

Eighteen different PAHs were screened for in samples with their characteristic $\mathrm{m} / \mathrm{z}$ (Table 1). Additionally, samples were screened for both long and short $n$-alkanes, as well as some other proxies relating to biological communities including steranes, hopanes and oleanane. 
In all samples there is noticeable spike in all compounds analyzed, except for long chain $n$-alkanes (LCA), right around the boundary at 20.10 meters, between 20.14 and $19.98 \mathrm{~m}$. Perylene is the most abundant PAH (41.82 ng/g sediment, $20.04 \mathrm{~m}$ ), right after the boundary followed by Pyrene (40.43 ng/g sediment, $20.04 \mathrm{~m}$ ), and phenanthrene (13.98 ng/g sediment, $20.07 \mathrm{~m}$ ). Both, the low and high temperature PAHs exhibit a second spike between 19.0 and $18.38 \mathrm{~m}$. A sum of PAHs with less rings, associated with low temperatures of formation (Fig. 7A) demonstrates a cleaner signal with a spike at the boundary, a drop to pre-boundary levels, and a gradual increase as they move up the section, until it again returns to drop at the end of the sample set. All the low temperature PAHs follow this trend except for phenanthrene. This could be due to a different source for the PAH at that point as phenanthrene can form from combustion or diagenesis (Nabbefeld et al. 2010). However, up until that point phenanthrene followed the trend of other combustion derived compounds.

The compounds with a greater ring count indicative of high-temperature burning (Fig. 7E) portray a similar story, albeit their secondary spike occurs earlier in the record at around $19.19 \mathrm{~m}$ compared to low-temperature PAHs (Figs. 7A-D). The secondary spike at $19.19 \mathrm{~m}$ is mostly caused by benzo[e]pyrene ( $5.05 \mathrm{ng} / \mathrm{g}$ sediment) and coronene (1.93 ng/g sediment), as benzo[a]anthracene has a marked decrease at that very point $(1.12 \mathrm{ng} / \mathrm{g}$ sediment). The concentrations of benzo[e]pyrene and coronene then plummeted to a bare minimum where benzo[a]anthracene begins to climb and follow the trend of the lower temperature PAHs. It should be noted that benzo[e]pyrene is considered amongst the best representative of the original combustion products due to its stability (Nabbefeld et al. 2010). It is also closely associated with volcanic activity. 


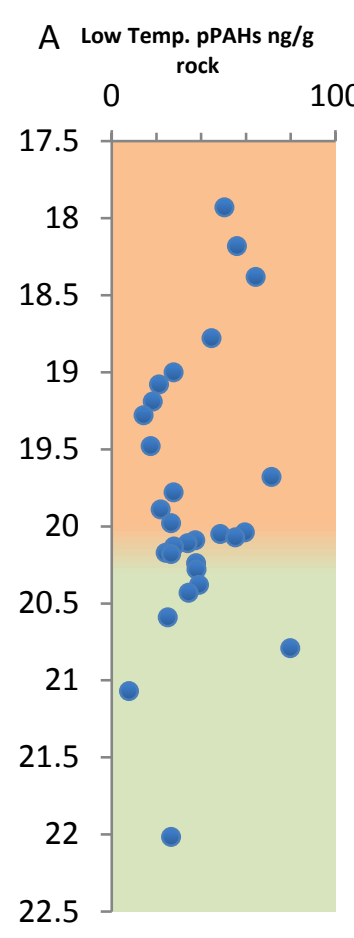

B Pyrene ng/g rock

C Flouranthene ng/g rock

D Phenanthrene $\mathrm{ng} / \mathrm{g}$ rock

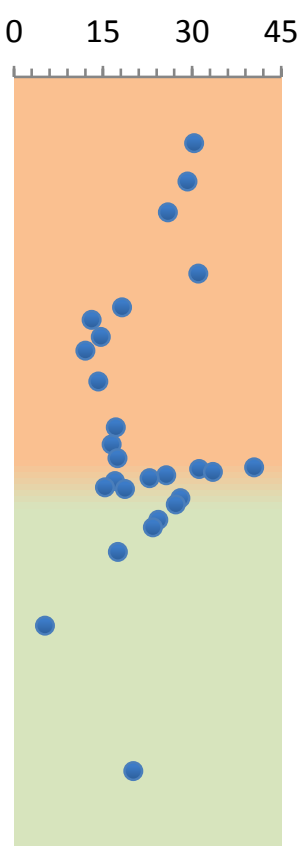

0

$10 \quad 20$

$\begin{array}{lll}0 & 10 & 20\end{array}$

E Hig-temp. PAHs ng/g rock

F
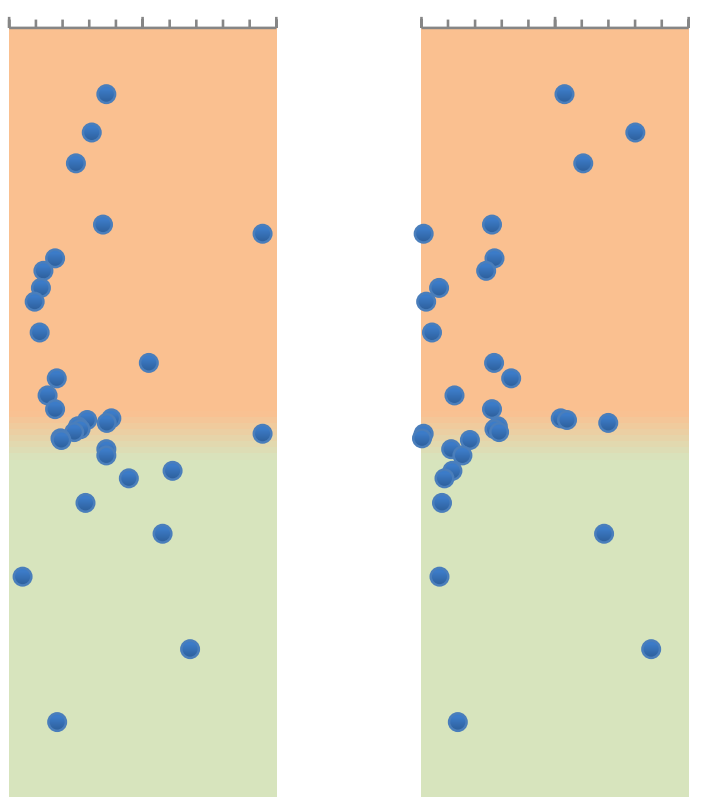

$\begin{array}{lll}0 & 25 \quad 50\end{array}$

F Benz[a]anthracene $\mathrm{ng} / \mathrm{g}$

G Benzo[e]pyrene ng/g rock
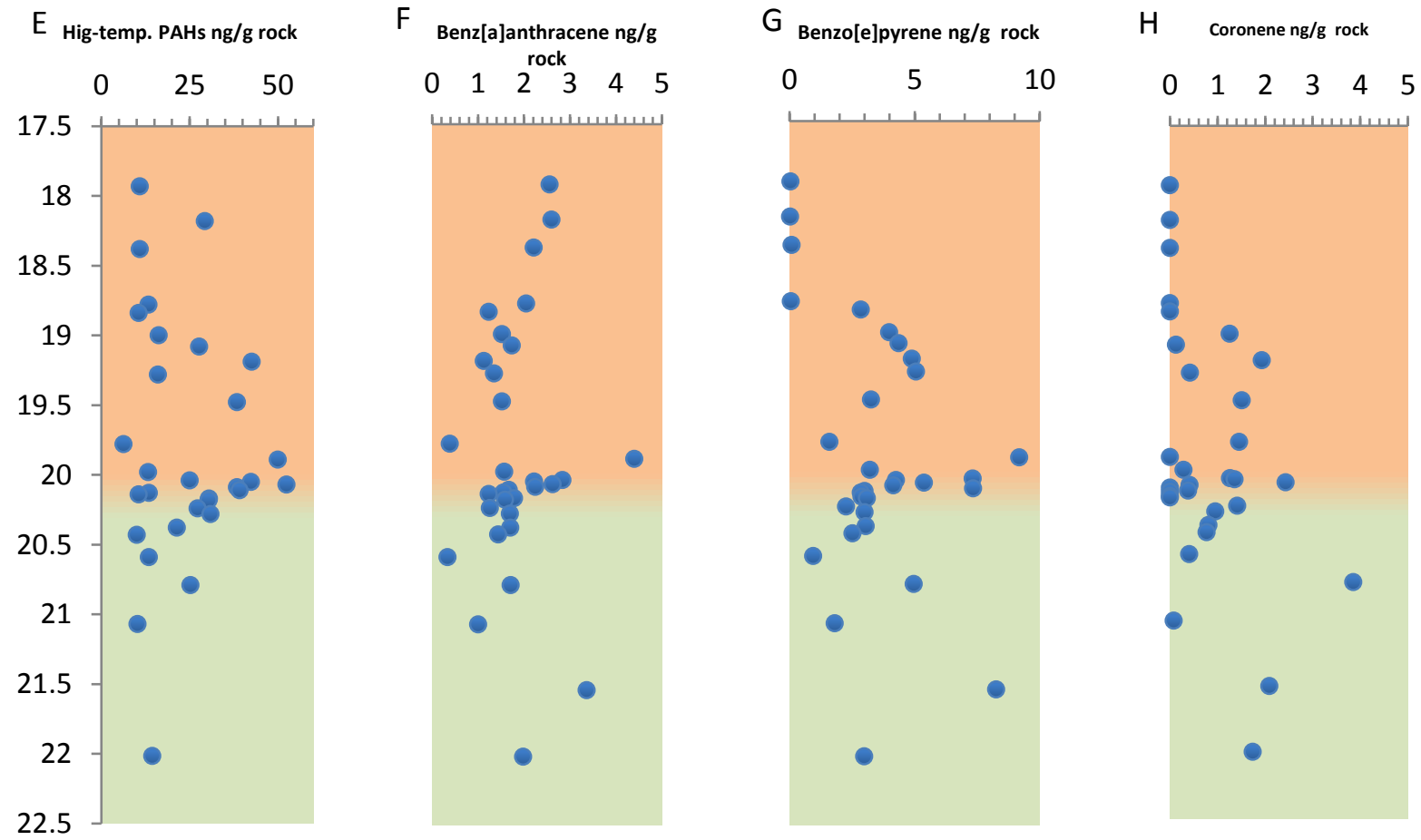

0
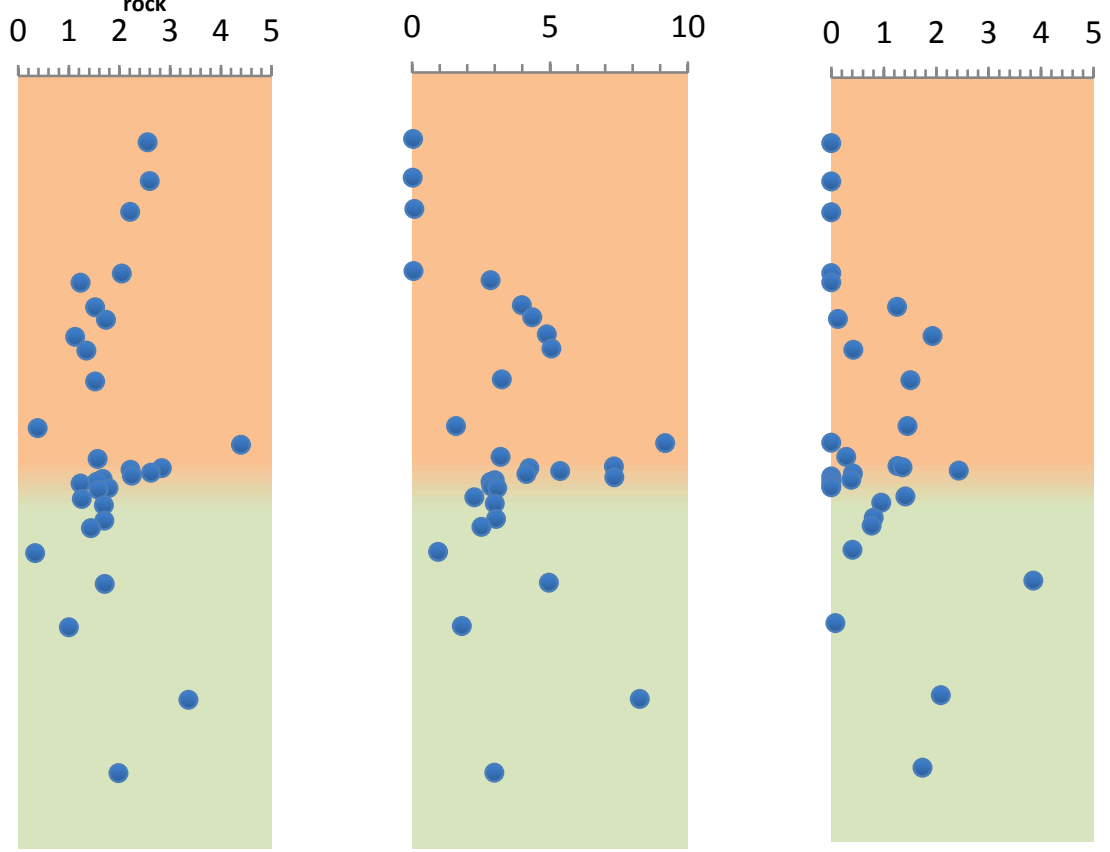

Figure 8: Stratigraphy Columns for the el Kef core. K-Pg boundary is at $\simeq 20.10 \mathrm{~m}$ which can be seen by the change in colors from green to red. A-D represent PAHs of low temperature of combustion due to the decreased ring number, whereas E-H represent higher temperature PAHs of formation due to their many aromatic rings. 


\section{A Retene $\mathrm{ng} / \mathrm{g}$ rock}

$\begin{array}{lll}0.0 & 0.2 & 0.4\end{array}$

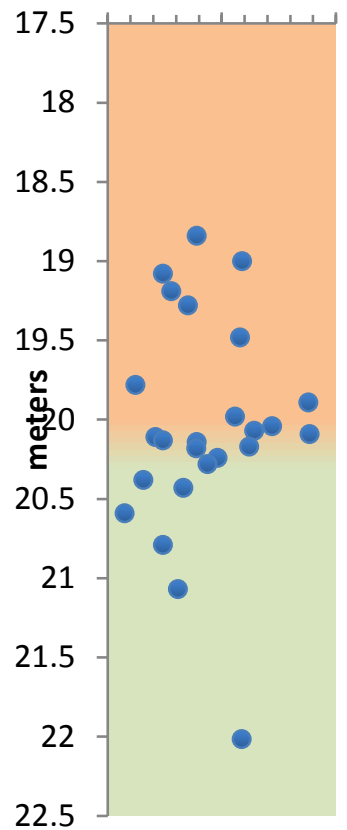

E

Hop/Ster

$\begin{array}{llll}0 & 15 & 30 & 45\end{array}$

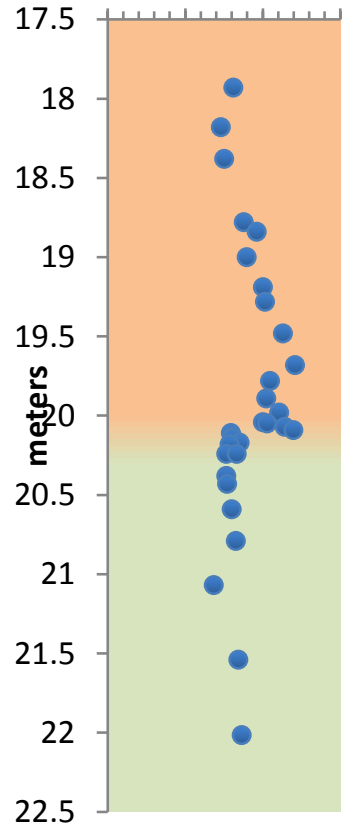

B Perylene ng/g rock

50

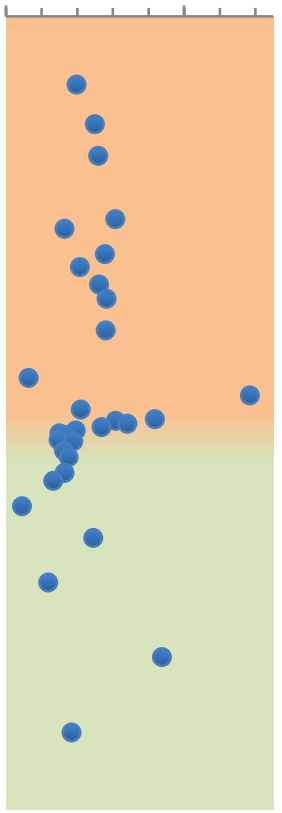

F

ug SCA/g rock
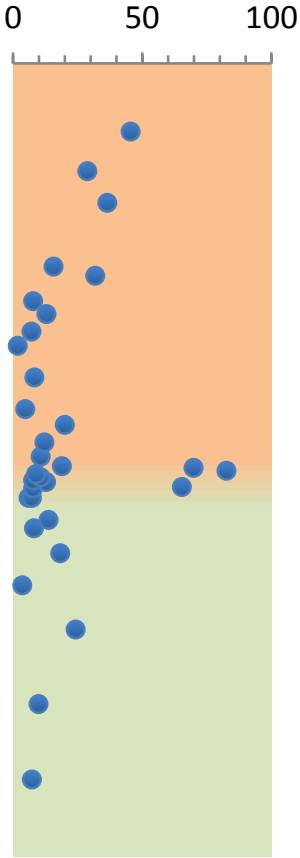

C Oleanane $\mathrm{ng} / \mathrm{g}$ rock

D
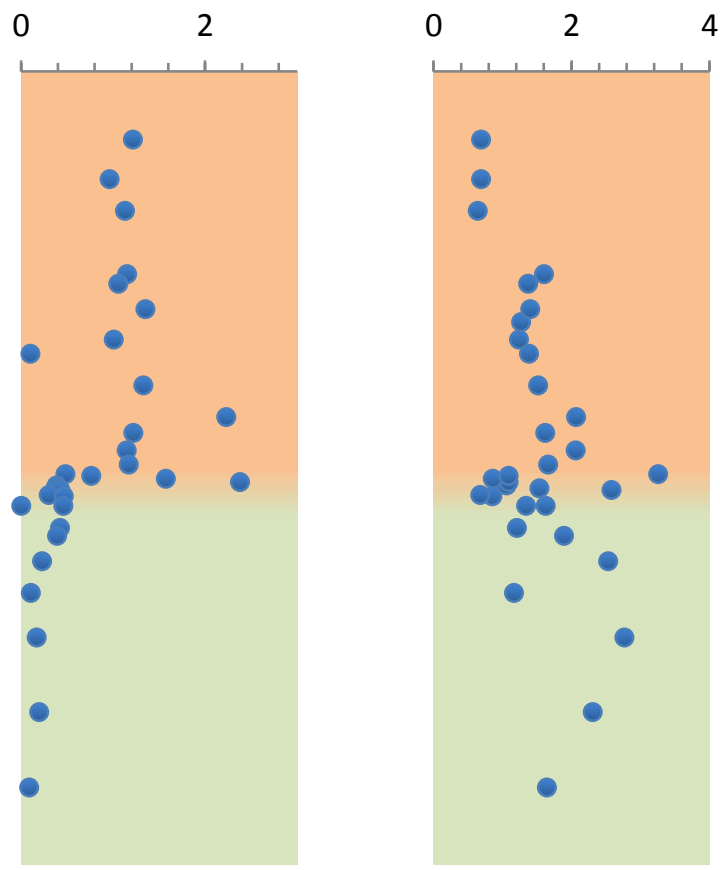

G

ug LCA/g rock

40

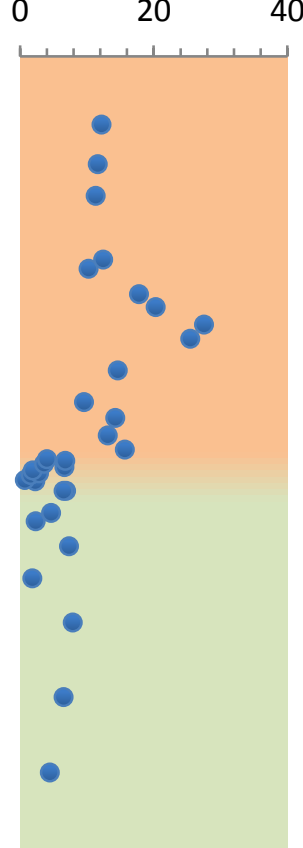

H LCA/SCA
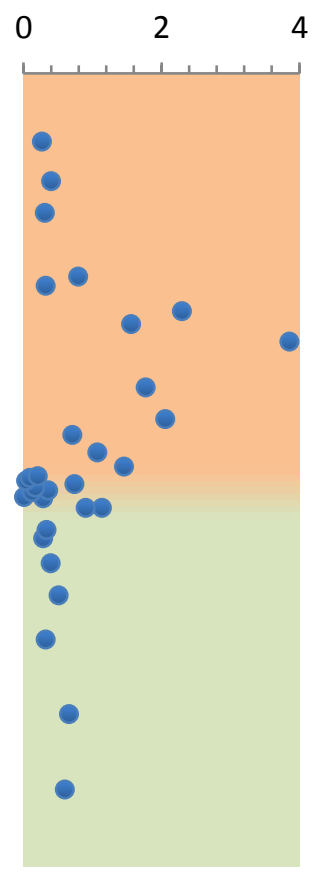

Figure 9: Stratigraphy Columns for the El Kef core. Column details the changes in concertation for Retene, a PAH derived from the diagenesis of abeitic acid from confier resins. B plots perylene, a PAH associated with fungal decomposition. Oleanane, a triterpene, is present in angiosperms and serves to approximate their abundance through time. $D$ is the Carbon Preference Index, the ratio between odd numbered carbon vs even numbered $n$-alkanes. $E$ is the ratio of hopanes over steranes, a proxy for bacterial over algal contributions whilst $F$ and $G$ are the short and long chain $n$-alkanes respectively. $H$ is the ratio of $F$ over $G$. 


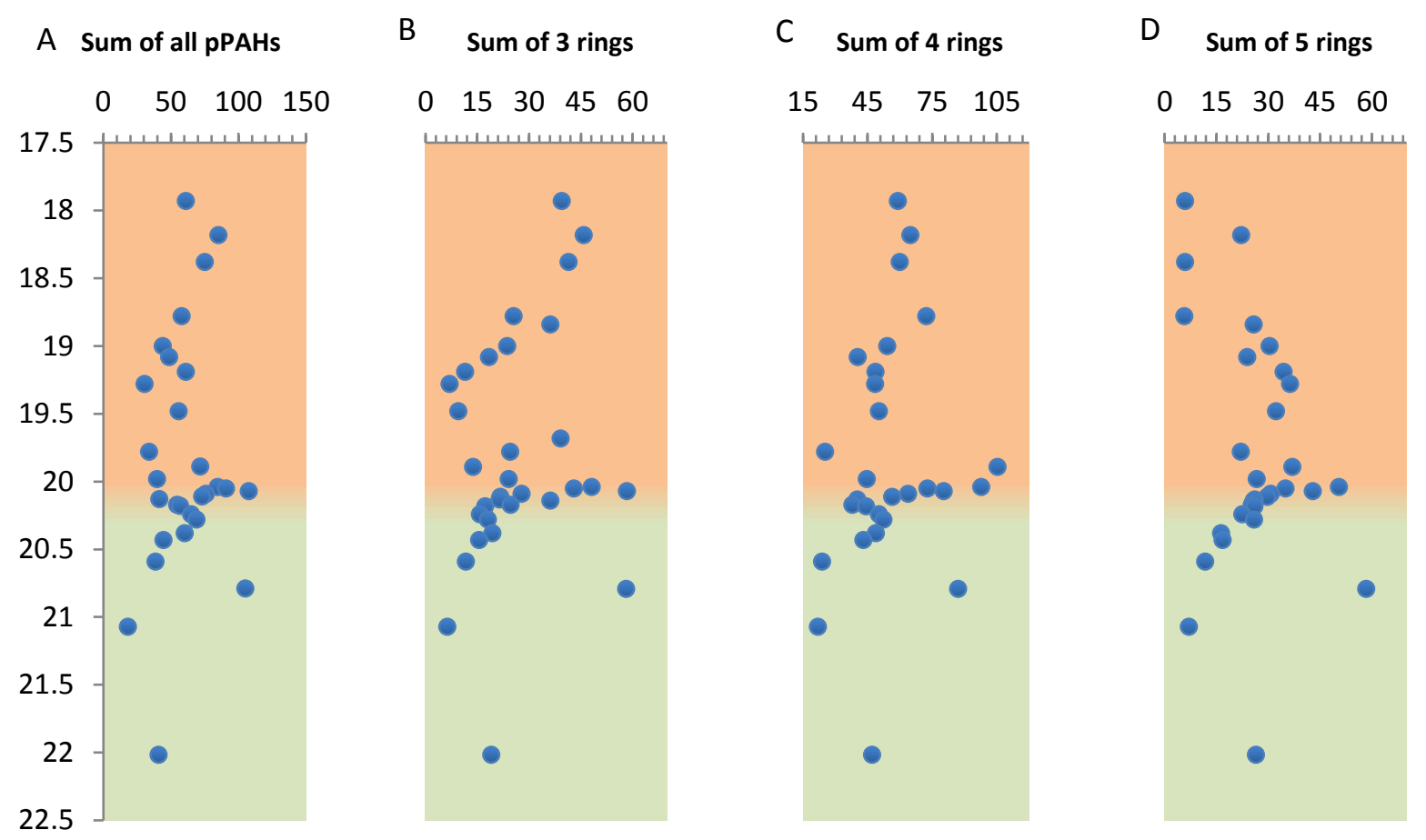

Figure 10: Stratigraphy Columns for the el Kef core. A is a total sum of all pyrosynethetic PAHs with B being a total of compounds with three rings, $C$ being four rings, and $D$ being five rings.

The vegetation related biomarkers Figure $9(A-C)$ all show a spike around the boundary but the exact points between show some variability. For instance, perylene and retene display their spikes at $19.89 \mathrm{~m}$ with concentrations of $0.35 \mathrm{ng} / \mathrm{g}$ sediment and $68.41 \mathrm{ng} / \mathrm{g}$ sediment respectively whilst oleanane has its spike a little lower in the section at $20.09 \mathrm{~m}$ with a concentration of $2.4 \mathrm{ng} / \mathrm{g}$ sediment. This could be due sediment reworking and or bioturbation but concentrations of oleanane at $19.89 \mathrm{~m}$ (1.2 ng/g sediment) are still higher than the background. The carbon preference index (CPI) of the, a ratio of odd over even $n$-alkanes, also demonstrates a spike right before the boundary to about 3.3 at $20.04 \mathrm{~m}$.

Long Chain $n$-alkanes (LCA) Figure $9 \mathrm{G}$ are the only stratigraphic column to not exhibit a spike in concentration with a concentration of $4 \mu \mathrm{g} / \mathrm{g}$ sediment. There is a spike at $19.19 \mathrm{~m}$ to a concentration of 
$27.5 \mu \mathrm{g} / \mathrm{g}$ sediment which correlates with the secondary spike for high temperature PAHs and like them return to background values within 10-15 cm. Short chain $n$-alkanes (SCA) Figure 9F display a marked increase right above the boundary at $20.07 \mathrm{~m}$ with a concentration of concentration of $82.7 \mu \mathrm{g} / \mathrm{g}$ sediment wherein concentrations return to pre-boundary levels with the beginnings of a gradual increase after $19 \mathrm{~m}$. Figure $9 \mathrm{H}$ of LCA/SCA reflects the marked increase in long chain $n$ alkanes. Hopanes/Steranes and Hopanes (Fig. 8E) displays a shallow increase but return to background levels and do not exhibit anymore deviations from then until the top of the study area.

Sums of the total PAH abundance for different ring numbers was also graphed in Figure 9, illustrating similar spikes at the boundary but revealing 3-4 ring PAHs secondary spikes inversely related to 5 ring compounds. A total sum of all PAHs (Fig. 10A) demonstrates an overall concentration of $107.7 \mathrm{ng} / \mathrm{g}$ sediment at $20.07 \mathrm{~m}$ right before the boundary. A secondary spike occurs at $18.18 \mathrm{~m}$ with a concentration of $85.2 \mathrm{ng} / \mathrm{g}$ sediment. As the quantity of 3-4 rings is greater and they are correlated with one another, they essentially force the trend in the total PAH record.

\begin{tabular}{|lcc|}
\hline Compund Name & M/Z & Source \\
\hline Napthalene & 128 & $\mathrm{P}$ \\
\hline Flourene & 166 & $\mathrm{P}$ \\
\hline Phenanthrene & 178 & $\mathrm{P}, \mathrm{D}$ \\
\hline Anthracene & 178 & $\mathrm{P}$ \\
\hline Flouranthene & 202 & $\mathrm{P}$ \\
\hline Pyrene & 202 & $\mathrm{P}$ \\
\hline retene & 219 & $\mathrm{D}$ \\
\hline Benz[a]anthracene & 228 & $\mathrm{P}$ \\
\hline Chrysene & 228 & $\mathrm{P}, \mathrm{D}$ \\
\hline triphenylene & 228 & $\mathrm{P}, \mathrm{D}$ \\
\hline Benzoflouranthenes & 252 & $\mathrm{P}$ \\
\hline Benzo[e]pyrene & 252 & $\mathrm{P}$ \\
\hline Benzo[a]pyrene & 252 & $\mathrm{P}$ \\
\hline perylene & 252 & $\mathrm{D}$ \\
\hline Dibenz[a,h]anthracene & 276 & $\mathrm{P}$ \\
\hline indeno[ce-123]pyrene & 276 & $\mathrm{D}$ \\
\hline Benzo[g,h,i]perylene & 276 & $\mathrm{P}, \mathrm{D}$ \\
\hline Coronene & 300 & $\mathrm{P}$ \\
\hline
\end{tabular}

Table 1: Name, molecular mass $\left(\mathrm{M}^{+}\right)$, and source for the 18 PAHs in this study *Benzoflouranthenes are a compilation of members $b, j$, and $k . P$ is pyrogenic, while $D$ is diagenetic. 


\section{Discussion}

PAHs like coronene, benzo[e]pyrene, fluoranthene, benzo[a]anthracene, phenanthrene, and pyrene have all been ascribed to combustion [34,39]. All these compounds exhibit notable increases across the boundary, with secondary spikes throughout the section. To understand the happenings of the extinction, some of the above graphs have been reorganized around the immediate pre- and post- $\mathrm{K} / \mathrm{Pg}$ boundary to give a better resolution of the series of events that took place, and to facilitate their comparison with other records from the literature.
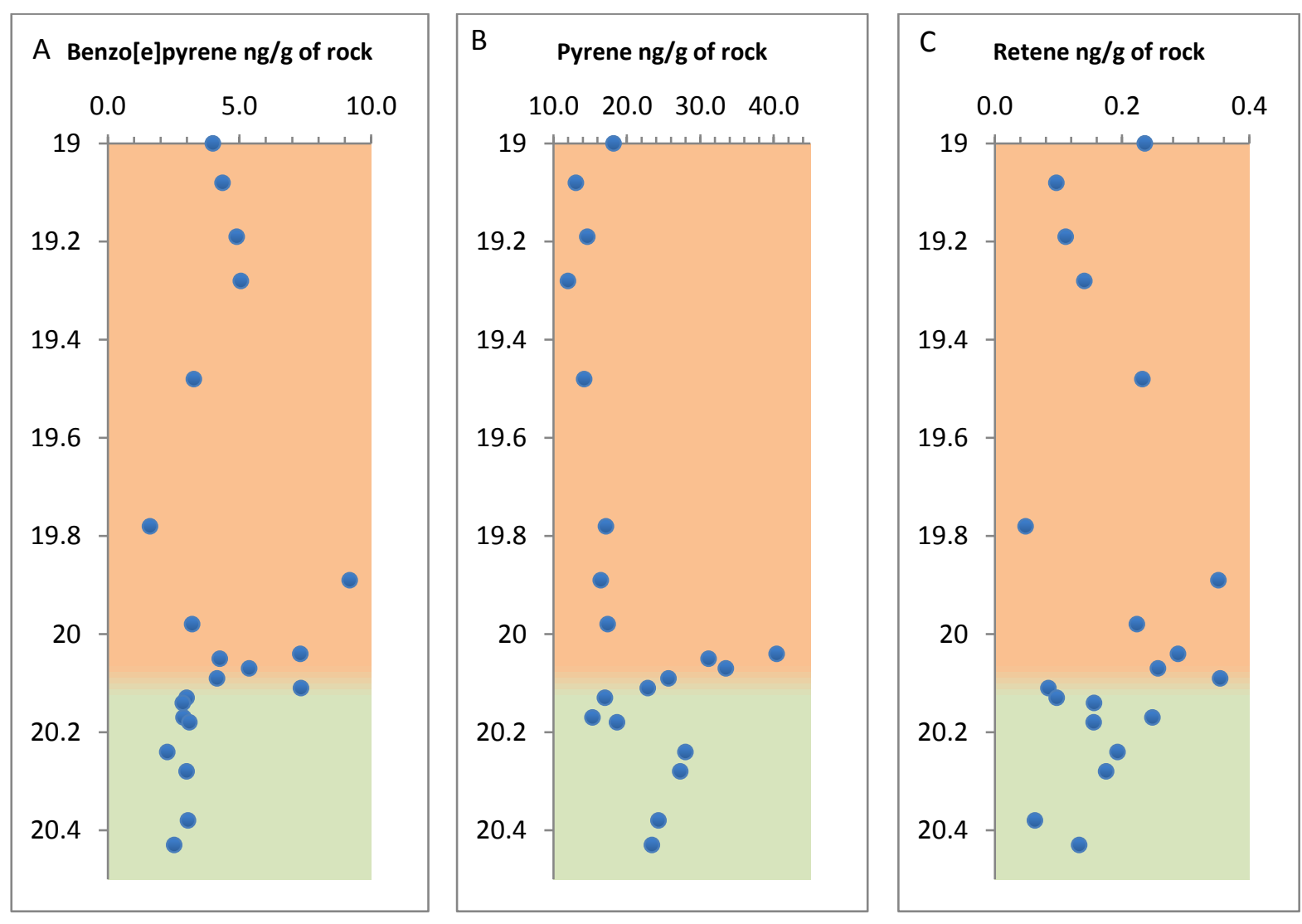

Figure 11: A 'close up" of the earlier stratigraphy columns for the El Kef core. Note the better-quality signal and resolution of high temperature PAHs (A), low temperature PAHs (B), and coniferous resins (C).

Benzo[e]pyrene, pyrene and retene show a similar patter as previously described for other sections worldwide (Fig. 11). Using a sedimentation rate for the clay layer calculated from the outcrop $(7.96 \pm 1.30 \mathrm{~cm} / \mathrm{kyr}$; Giron, 2013) provides some context of the timing of events. Around $126 \mathrm{~cm}$ above the $\mathrm{K} / \mathrm{Pg}$ (around $15.8 \pm 0.2 \mathrm{kyrs}$ ) a spike of low temperature PAHs is 
evident. Estimates for the time it may have taken for the extinction to occur are as short as a couple years up to ten years (Kaiho et al. 2016). The post-impact cooling event did not have any long-lasting climate perturbations and must have returned to "normal" background conditions after 0-3 ky (Kaiho et al. 1999). Thus, the spike further up the section may not even have any relations to the extinction itself.

In comparison, Arinobu et al. (1999) reported a section that spanned $40 \mathrm{~cm}$ and right around the boundary at Caravaca. As stated above, Venkatesan and Dahl (1989) reported enhanced levels of phenanthrene, anthracene, pyrene and fluoranthene across the K-Pg boundary in sections from New Zealand, Italy, and Denmark, which validates the finding of this study. Moreover, pyrene, fluoranthene, chrysene and benzo(a)anthracene have been found across the K/Pg in Arroyo el Mimbral, Tamaulipas, Mexico. While chrysene shows the same trend as other pyrosynthetic PAHs across the Permian-Triassic extinction event, Nabbelfield et al. 2010 indicates that it can be formed from diagenesis, like phenanthrene The presence of pyrolytic PAHs of increasing ring size can be used to infer the definite combustion of organic matter, while using the number of rings in those structures can be related to the temperature of combustion. PAHs then reveal inputs from combustion, perhaps from the landmass proximal to the continental margin. PAH's typically adsorb onto soot surfaces via hydrogen bonding and could have travelled through either the troposphere and/or stratosphere to finally arrive and be deposited at El Kef. Though 3-ring compounds are by themselves more abundant than other ring numbers, combined 4-5 ring compounds dominate the record overall. This indicates moderate to high temperatures of combustion (Killops \& Massoud 1992). An interesting relationship is that the first episode of global conflagration via combustion of hydrocarbons at the impact rock and/or biomass burning was right at the boundary, where a spike in lower temperature fires occurred. If those fires could generate enough soot and cause partial desiccation of plants and death of forests, then they would become the perfect tinder to start even more and hotter fires. Perhaps that is why we see first the lower temperature PAHs followed by a spike of the higher temperature PAHs. 


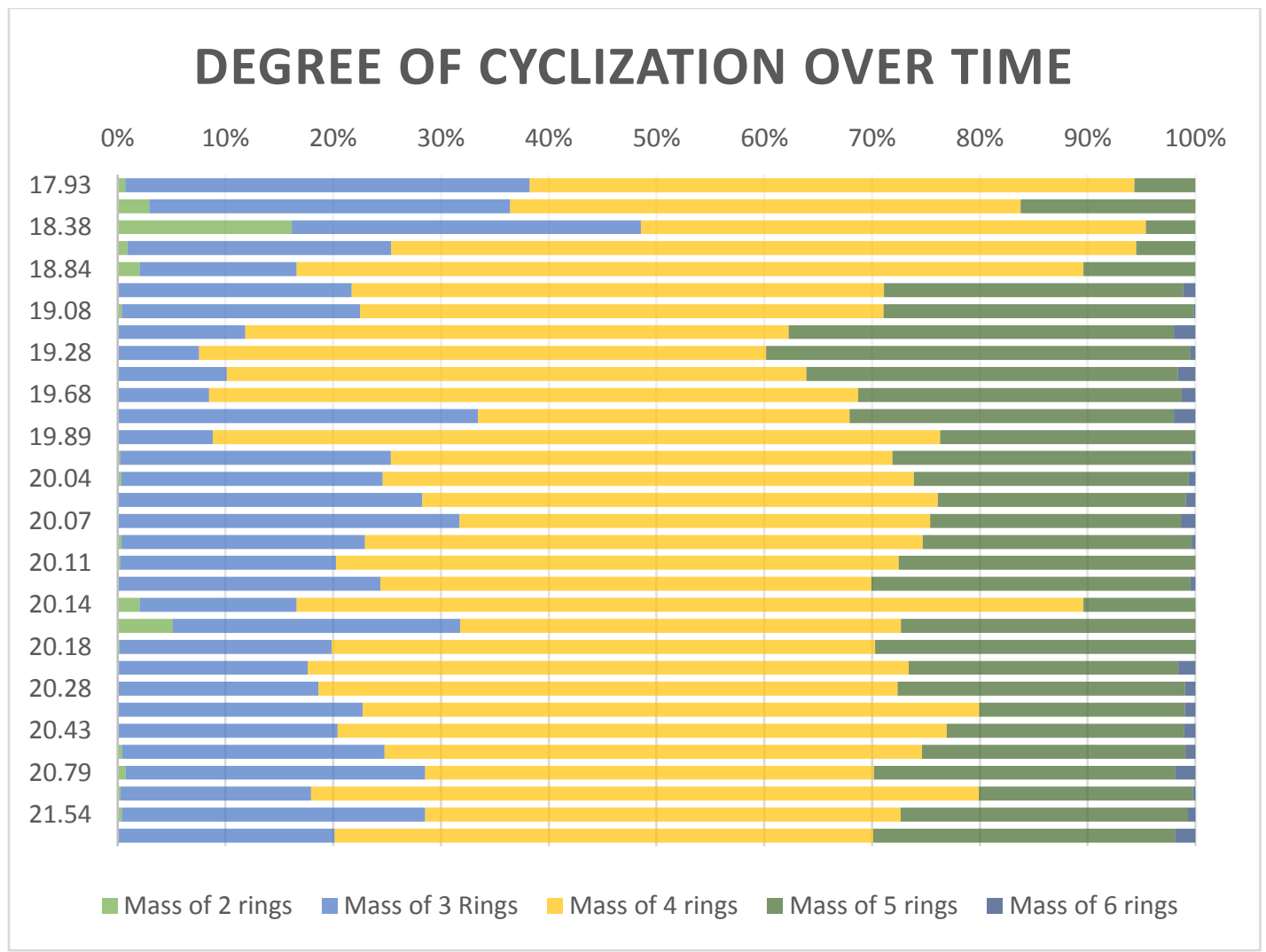

Figure 12: Change in the degree of cyclization of PAHs over time. Note the sudden increases in 4 and or 3 ring members but the trend overall does not change greatly.

The degree of cyclization over time does not show any great variability near the boundary suggesting that whatever was causing wildfires beforehand continued to do so at the boundary. Essentialy, there does not seem to be any source such as hydrocarbons causing the increase in PAH concentrations at the boundary.

Retene has been used in several studies as a derivative of abietic acid, a resin in coniferous plants and a good proxy for vegetation and terrestrial input. Retene shows a slight increase in concentration at the same point the high-temperature PAHs show a spike (Nabbefeld et al. 2010). This could be due to impact related combustion and eventual erosion after the global cooling episode passed. Perylene, a biomarker derived from fungal sources (Nabbefeld et al. 2010) also bears a spike in concentration at that interval (19.89 m). A simple scenario of impact related combustion could have burned and or killed forests, opening the way for detritivores to bloom wherein the hydrologic cycle could have recovered eroding the bare and loose earth upon which forests once stood. 
Oleanane also bears a spike but one that correlates more with that of Figure 8A. Perhaps there were selective fires for different regimes of plants, allowing angiosperms to burn at lower temperatures. Of note though is that the other vegetation marker indicates a spike around or at the boundary, and a subsequent return to pre-boundary levels. This is not the case with oleanane as its concertation spiked and then went down, but never returned, possibly indicating their entry into new habitats.

Due to the impact winter, terrestrial input may have been suppressed from the reduction in precipitation, and when that abated and a warming episode began, terrestrial organic matter may have made its way to a coastal setting due to continental runoff. Longchain $n$-alkanes (LCA) can also be transported by aeolian means, but interestingly, an increase in LCA is noted at the same time as the high temperature PAHs spiked for a second time after the $\mathrm{K} / \mathrm{Pg}$ (Fig. 8A). At the same time, there is a marked drop in short-chain $n$-alkanes (SCA) immediately following a large spike (Fig. 9F). It has been postulated that upwelling may have caused algal blooms (Frank et al. 2005). SCA then dropped drastically and only began a gradual recovery up the section. Another hypothesis is that the terrestrial input from post-fire erosion is responsible for the spike, despite the LCA decrease as SCA increase but that could be again to aeolian transport of leaf waxes.

The carbon preference index (CPI) of LCA follows the same trend as all the other compounds with an increase at the boundary. Higher plants have an odd over even preference of LCAs versus the even over odd preference exhibited by aquatic sources for both SCA and LCA. Thus, the CPI can be used as an additional indicator of terrestrial input, as a high CPI is indicative of an enhanced preference for odd numbered $n$-alkanes from plant waxes, while a $\mathrm{CPI}$ of 1 or below is more indicative of aquatic sources, or alternatively, to mature hydrocarbons sources. If there was a huge hydrocarbon reservoir, the likes of which that would be able to cause global cooling, then it would influence the CPI values pointing to a firestorm scenario. This contrast sharply then with the findings in Kaiho et al. 2016. 
Lastly, the total bacterial hopanes over total algal steranes show a large increaset of bacterial biomass right after the $\mathrm{K} / \mathrm{Pg}$ boundary. This could be due to enhanced continental runoff and the transport of soil bacterial biomass into the marine realm.

Before the boundary, PAH concentrations already seem to be increasing which begs the question as to why that is occurring. It could be due to reworking as there is some evidence to that effect (Keller 1995) or it could be due to some other sorts of combustion leading up that event. However, the presence of iriduium at that discrete point as well as nanofossil assemblages place that PAH spike at the boundary.

Some issues with sampling could give rise to that spike as well. Samples at the boundary are marked by $1 \mathrm{~cm}$ intervals but as sample distance from the boundary increases, the sample interval size increases to around 2,3 and in some cases $4 \mathrm{~cm}$. This could cause an inordinate amount of integration of concentrations that could throw off measurements and perhaps be responsible for the amount of noise in the measurements.

Although concentrations ( $\mathrm{ng} / \mathrm{g}$ rock) are good preliminary data to begin understanding initial relationships in the rock record, they are just that and do not consider different rates of sedimentation. Mass accumulation rates for the outcrop are variable and need to be further constrained allowing for a better representation of data by plotting mass over time (flux). Lastly, statistical analysis of any kind was not used for this study and should be employed to ensure reasonable exclusion of certain points.

\section{Conclusions}

Drill core samples of the K/Pg GSSP section at El Kef reveal a spike in a host of biomarkers including pyrogenic PAHs of varying cyclization, $n$-alkanes and vegetation proxies across the $\mathrm{K} / \mathrm{Pg}$ boundary. This surge provides a mechanism detailing the cascade of environmental events resulting from the impactor to the eventual extinction. Impact models have predicted a worldwide thermal pulse after the impact (Melosh et al. 1990). Ejecta from the bolide would be the primary culprit, as after they vaporize and precipitate, they fall through 
the stratosphere causing further heating and spreading of that heat far from the impact site that would easily desiccate plants and most life that was not sheltered from the impact. As a result from the falling flaming debris, forest fires would ignite and from them a soot would form from incomplete combustion. As stated above, soot does not typically enter the troposphere, but given an intense enough conflagration, soot would be able to invade and stay in the stratosphere for some time causing a global cooling episode. The global cooling would then slow down the hydrologic cycle causing drought like conditions all over the earth beginning the extinction event.

PAHs are excellent proxies for paleo-wildfires as they have a long resident time due to their recalcitrance but also due to the number of rings that determines the heat of formation. It was found in the El Kef GSSP through selective reaction monitoring mass spectrometry, that $\mathrm{PAH}$ levels are elevated around the boundary. Both high- and low-temperature PAHs were found, which were most prominent in different areas of the stratigraphic record, with the lowtemperature forms preceding the high-temperature ones. This is thought to be due to an initial ignition of biomass that spreads its way to desiccated and dead forests that would burn at a higher temperature. Vegetative biomarkers like perylene and retene show an increase after the higher intensity burning episode and decrease. On the other hand, oleanane from angiosperms spikes near the boundary and subsequently drops, but not to pre-boundary levels, indicating a potential advantageous takeover of new habitats from this group. Furthermore, these spikes reflect a level of increased terrestrial input several thousand years after the boundary. Marine productivity shows a spike at the boundary with a decrease for about a meter until it gradually begins to increase again. This sharp increase across the boundary is most likely due to algal blooms during increased terrestrial or enhanced upwelling of nutrients. Hopanes over steranes also supports the idea of increased terrestrial input after the impact, as soils that were affected by fires may have then saturated and become transported by runoff. Therefore, this trend is most likely representing an increase in soil bacterial biomass rather than a collapse of algal productivity.

As is seen from figure 12 , the $\mathrm{PAH}$ ring count over time does not change indicating that whatever the source of combustion pre-boundary did not change entering the Paleogene. This 
suggests that the source never changed and there was not some sudden spike in high temperature PAHs as compared to before or after. Sedimentation rates also need to be further constrained to allow for more accurate depictions of the flux of PAHs into sediments over time.

\section{Future Studies}

The K-Pg mass extinction is important but description of the section by itself is meaningless without the context around it. That is why further analysis of the cores surrounding the K-Pg are necessary. Some other considerations are isotopic analysis of the PAHs via $\Delta^{14} \mathrm{C}$ analysis to determine if they are sourced from combustion of biomass or a hydrocarbon reservoir. Additionally, the use of the SRM method for detection can also be applied to other sections to see if the higher ring number PAHs' signal can be increased to see if they concur with the findings in this study.

\section{Acknowledgments}

The author is grateful to Julio Sepulveda of the University of Colorado at Boulder for providing samples and mentoring through the process, Nadia Diladar and Frank Garret Boudinot of the University of Colorado of Boulder for the expertly executed processing and generation of data via GC-SRM-MS. Furthermore, great thanks goes out to Marwa Baroumi of the University of Tunis for the n-alkane data generation as well as Hedi Negre of the University of Tunis for leading the drilling program as well as great thanks to the rest of El Kef Core Drilling Project. Lastly the author would like to thank the illustrious members of this honors committee, Charles Stern and Eve-Lyn Hinckley 


\section{$\underline{\text { References }}$}

Alroy, John. "Taxonomic Inflation And Body Mass Distributions In North American Fossil Mammals." Journal of Mammalogy 84.2 (2003): 431-43. Web.

Alvarez, L. W., W. Alvarez, F. Asaro, and H. V. Michel. "Extraterrestrial Cause for the CretaceousTertiary Extinction." Science 208.4448 (1980): 1095-108. Web.

Arinobu, Tetsuya, Ryoshi Ishiwatari, Kunio Kaiho, and Marcos A. Lamolda. "Spike of Pyrosynthetic Polycyclic Aromatic Hydrocarbons Associated with an Abrupt Decrease in I'́13C of a Terrestrial Biomarker at the Cretaceous-Tertiary Boundary at Caravaca, Spain." Geology 27.8 (1999): 723. Web.

Belcher, C. M. "Impacts and Wildfires - An Analysis of the K-T Event." Impact Studies Biological Processes Associated with Impact Events (n.d.): 221-43. Web.

Belcher, C. M., P. Finch, M. E. Collinson, A. C. Scott, and N. V. Grassineau. "Geochemical Evidence for Combustion of Hydrocarbons during the K-T Impact Event." Proceedings of the National Academy of Sciences 106.11 (2009): 4112-117. Web.

Fastovsky, David E., and Peter M. Sheehan. "The Extinction of the Dinosaurs in North America." GSA Today 15.3 (2005): 4. Web.

FINKELSTEIN, DAVID B., LISA M. PRATT, TARA M. CURTIN, and SIMON C. BRASSELL. "Wildfires and Seasonal Aridity Recorded in Late Cretaceous Strata from South- eastern Arizona, USA." Sedimentology. Blackwell Science Ltd, 18 May 2005. Web. 07 Apr. 2017.

Fromm, Michael. "Pyro-cumulonimbus Injection of Smoke to the Stratosphere: Observations and Impact of a Super Blowup in Northwestern Canada on 3â€ " 4 August 1998." Journal of Geophysical Research 110.D8 (2005): n. pag. Web.

Goldin, T. J., and H. J. Melosh. "Self-shielding of Thermal Radiation by Chicxulub Impact Ejecta: Firestorm or Fizzle?" Geology 37.12 (2009): 1135-138. Web.

Harvey, Mark C., Simon C. Brassell, Claire M. Belcher, and Alessandro Montanari. "Combustion of Fossil Organic Matter at the Cretaceous-Paleogene (K-P) Boundary." Geology 36.5 (2008): 355. Web.

Hildebrand, Alan R., Glen T. Penfield, David A. Kring, Mark Pilkington, Antonio Camargo Z., Stein B. Jacobsen, and William V. Boynton. "Chicxulub Crater: A Possible Cretaceous/Tertiary Boundary Impact Crater on the Yucat $\tilde{j}_{i n}$ Peninsula, Mexico." Geology 19.9 (1991): 867. Web.

Jiang, Chunqing, Robert Alexander, Robert I. Kagi, and Andrew P. Murray. "Polycyclic Aromatic Hydrocarbons in Ancient Sediments and Their Relationships to Palaeoclimate." Organic Geochemistry 29.5-7 (1998): 1721-735. Web.

Kaiho, Kunio, and Marcos A. Lamolda. "Catastrophic Extinction of Planktonic Foraminifera at the Cretaceous-Tertiary Boundary Evidenced by Stable Isotopes and Foraminiferal Abundance at Caravaca, Spain." Geology 27.4 (1999): 355. Web.

Kaiho, Kunio, Naga Oshima, Kouji Adachi, Yukimasa Adachi, Takuya Mizukami, Megumu Fujibayashi, and Ryosuke Saito. "Global Climate Change Driven by Soot at the K-Pg Boundary as the Cause of the Mass Extinction." Scientific Reports 6.1 (2016): n. pag. Web.

Kaiho, Kunio, Yoshimichi Kajiwara, Kazue Tazaki, Masato Ueshima, Nobuyori Takeda, Hodaka Kawahata, Tetsuya Arinobu, Ryoshi Ishiwatari, Akio Hirai, and Marcos A. Lamolda. "Oceanic Primary Productivity and Dissolved Oxygen Levels at the Cretaceous/Tertiary Boundary: Their Decrease, Subsequent Warming, and Recovery." Paleoceanography 14.4 (1999): 511-24. Web. 
Keller, G., and M. Lindinger. "Stable Isotope, TOC and CaCO3 Record across the Cretaceous/tertiary Boundary at El Kef, Tunisia." Palaeogeography, Palaeoclimatology, Palaeoecology 73.3-4 (1989): 243-65. Web.

Keller, G., L. Li, and N. Macleod. "The Cretaceous/Tertiary Boundary Stratotype Section at El Kef, Tunisia: How Catastrophic Was the Mass Extinction?" Palaeogeography, Palaeoclimatology, Palaeoecology 119.3-4 (1996): 221-54. Web.

Killops, S.d., and M.s. Massoud. "Polycyclic Aromatic Hydrocarbons of Pyrolytic Origin in Ancient Sediments: Evidence for Jurassic Vegetation Fires." Organic Geochemistry 18.1 (1992): 1-7. Web.

Kring, David A. "The Chicxulub Impact Event and Its Environmental Consequences at the Cretaceousâ $\square$ "Tertiary Boundary." Palaeogeography, Palaeoclimatology, Palaeoecology 255.12 (2007): 4-21. Web.

Lamolda, Marcos A., Mihaela C. Melinte, and Kunio Kaiho. "Nanofloral Extinction and Survivorship across the K/T Boundary at Caravaca, Southeastern Spain." Palaeogeography,Palaeoclimatology, Palaeoecology, 23 Mar. 2005. Web.

Melosh, H. J., N. M. Schneider, K. J. Zahnle, and D. Latham. "Ignition of Global Wildfires at the Cretaceous/Tertiary Boundary." Nature 343.6255 (1990): 251-54. Web.

Nabbefeld, Birgit, Kliti Grice, Roger E. Summons, Lindsay E. Hays, and Changqun Cao. "Significance of Polycyclic Aromatic Hydrocarbons (PAHs) in Permian/Triassic Boundary Sections." Applied Geochemistry 25.9 (2010): 1374-382. Web.

Novakov, T., Dean A. Hegg, and Peter V. Hobbs. "Airborne Measurements of Carbonaceous Aerosols on the East Coast of the United States." Journal of Geophysical Research: Atmospheres 102.D25 (1997): 30023-0030. Web.

Pope, Kevin O. "Impact Dust Not the Cause of the Cretaceous-Tertiary Mass Extinction." Geology 30.2 (2002): 99. Web.

Pope, Kevin O., Kevin H. Baines, Adriana C. Ocampo, and Boris A. Ivanov. "Energy, Volatile Production, and Climatic Effects of the Chicxulub Cretaceous/Tertiary Impact." Journal of Geophysical Research: Planets 102.E9 (1997): 21645-1664. Web.

Punekar, Jahnavi, Gerta Keller, Hassan M. Khozyem, Thierry Adatte, Eric Font, and Jorge Spangenberg. "A Multi-proxy Approach to Decode the End-Cretaceous Mass Extinction." Palaeogeography, Palaeoclimatology, Palaeoecology 441 (2016): 116-36. Web.

Robertson, Douglas S., Malcolm C. Mckenna, Owen B. Toon, Sylvia Hope, and Jason A. Lillegraven. "Survival in the First Hours of the Cenozoic." Geological Society of America Bulletin 116.5 (2004): 760. Web.

Robertson, Douglas S., William M. Lewis, Peter M. Sheehan, and Owen B. Toon. "K-Pg Extinction: Reevaluation of the Heat-fire Hypothesis." Journal of Geophysical Research: Biogeosciences 118.1 (2013): 329-36. Web.

Schulte, P., L. Alegret, I. Arenillas, J. A. Arz, P. J. Barton, P. R. Bown, T. J. Bralower, G. L. Christeson, P. Claeys, C. S. Cockell, G. S. Collins, A. Deutsch, T. J. Goldin, K. Goto, J. M. Grajales-Nishimura, R. A. F. Grieve, S. P. S. Gulick, K. R. Johnson, W. Kiessling, C. Koeberl, D. A. Kring, K. G. Macleod, T. Matsui, J. Melosh, A. Montanari, J. V. Morgan, C. R. Neal, D. J. Nichols, R. D. Norris, E. Pierazzo, G. Ravizza, M. Rebolledo-Vieyra, W. U. Reimold, E. Robin, T. Salge, R. P. Speijer, A. R. Sweet, J. Urrutia-Fucugauchi, V. Vajda, M. T. Whalen, and P. S. Willumsen. "The Chicxulub Asteroid Impact and Mass Extinction at the Cretaceous-Paleogene Boundary." Science 327.5970 (2010): 1214-218. Web. 
Sheehan, Peter M., and David E. Fastovsky. "Major Extinctions of Land-dwelling Vertebrates at the Cretaceous-Tertiary Boundary, Eastern Montana." Geology 20.6 (1992): 556. Web.

Smit, J. "Extinction and Evolution of Planktonic Foraminifera after a Major Impact at the Cretaceous/Tertiary Boundary." Geological Society of America Special Papers Geological Implications of Impacts of Large Asteroids and Comets on the Earth (1982): 329-52. Web.

Sofiev, M., R. Vankevich, T. Ermakova, and J. Hakkarainen. "Global Mapping of Maximum Emission Heights and Resulting Vertical Profiles of Wildfire Emissions." Atmospheric Chemistry and Physics 13.14 (2013): 7039-052. Web.

StẪ1/4ben, D., U. Kramar, Z. Berner, W. Stinnesbeck, G. Keller, and T. Adatte. "Trace Elements, Stable Isotopes, and Clay Mineralogy of the Elles II Kâ $\square$ "T Boundary Section in Tunisia: Indications for Sea Level Fluctuations and Primary Productivity." Palaeogeography, Palaeoclimatology, Palaeoecology 178.3-4 (2002): 321-45. Web.

Venkatesan, M. I., and J. Dahl. "Organic Geochemical Evidence for Global Fires at the Cretaceous/Tertiary Boundary." Nature 338.6210 (1989): 57-60. Web.

Wolbach, Wendy S., Iain Gilmour, and Edward Anders. "Major Wildfires at the Cretaceous/Tertiary Boundary." Geological Society of America Special Papers Global Catastrophes in Earth History; An Interdisciplinary Conference on Impacts, Volcanism, and Mass Mortality (1990): 391-400. Web.

Wolbach, Wendy S., Susanna Widicus, and Frank T. Kyte. "A Search for Soot from Global Wildfires in Central Pacific Cretaceous-Tertiary Boundary and Other Extinction and Impact Horizon Sediments." Astrobiology 3.1 (2003): 91-97. Web. 